\title{
Fighting Corruption in Education: What Works and Who Benefits?:
}

\author{
Oana Borcan \\ Mikael Lindahl \\ Andreea Mitrut \\ University of East Anglia \\ University of Gothenburg, \\ University of Gothenburg, \\ CESifo, IFAU, IZA, UCLS \\ UCLS
}

We investigate the distributional consequences of a corruption-fighting initiative in Romania targeting the endemic fraud in a high-stakes high school exit exam, which introduced CCTV monitoring of the exam and credible punishment threats for teachers and students. We find that the campaign was effective in reducing corruption and, in particular, that monitoring increased the effectiveness of the punishment threats. Estimating the heterogeneous impact for students of different poverty status we show that curbing corruption led to a worrisome score gap increase between poor and non-poor students. Consequently, the poor students have reduced chances to enter an elite university.

Keywords: corruption; high-stakes exam; bribes; monitoring and punishment JEL codes: I21, I24, K42

\footnotetext{
†E-mail: O.Borcan@uea.ac.uk, Mikael.Lindahl@economics.gu.se and Andreea.Mitrut@economics.gu.se (corresponding author), respectively. All errors are our own. Andreea Mitrut and Oana Borcan gratefully acknowledge support from the Jan Wallanders and Tom Hedelius Foundation. Mikael Lindahl is a Royal Swedish Academy of Sciences Research Fellow supported by a grant from the Torsten and Ragnar Söderberg Foundation, and also acknowledges financial support from the Scientific Council of Sweden and the European Research Council [ERC starting grant 241161].* The authors thank two anonymous referees, the editor Mark Duggan, Matthew Lindquist, Randi Hjalmarsson, Brian Knight, Marco Manacorda, Erich Battistin, Pedro Dal Bo, David Weil, seminar participants at Brown University, the "Economics of Education and Education Policy" workshop, IFAU, Uppsala, UCLS, Stockholm School of Economics (SITE), SSB, Oslo, and Gothenburg University for valuable comments.
} 
Equality of educational opportunity is a key ingredient in a society that wants to promote growth and increase social mobility. A meritocratic education system increases the efficiency of how talented individuals are allocated by rewarding ability and not family income. However, in many countries, hurdles such as tuition fees and school and neighborhood segregation may reinforce inequality of opportunities across generations and increase inequality by limiting skill acquisition and access to higher education for poor individuals of high ability. An additional barrier to higher education, mostly prevalent in developing countries, is corruption in education, including bribes taken by teachers to facilitate admission to education or to inflate grades and scores on high-stakes exams. Moreover, corruption in education may act as an added tax, putting the poor students at a disadvantage and reducing, once more, equal access to human capital (see Transparency International's 2013 Global Corruption Report).

This paper analyzes the implications of the fight against corruption in a setting of endemic fraud, cheating, and grade selling in the public education system in Romania. Particularly, we investigate the efficiency and distributional consequences of a national anticorruption campaign targeting the Romanian high school exit exam - the Baccalaureate. ${ }^{1}$ The campaign was initiated in 2011 in response to the 2010 Baccalaureate, which marked a peak in corruption for exam grades and generated a media storm after the Romanian National Anticorruption Directorate revealed how batches of identical answers had been distributed to students by public teachers (see Borcan, Lindahl and Mitrut, 2014). ${ }^{2}$ The campaign consisted of two distinct components: 1) increasing the threat of punishment for teachers and students caught taking/giving bribes and 2) closed-circuit TV (CCTV) monitoring of the exam centers in an effort to eradicate mass cheating and bribes during the examination. Similar policies are currently discussed in other countries, and a few countries, such as Moldova, Cambodia and India have already implemented monitoring and harsher punishments targeting corruption in exams. CCTV monitoring has also penetrated higher education and regular classrooms, to combat cheating in university exams and to discipline school teachers and students in countries like the Netherlands and $\mathrm{UK}^{3}$

Our aim in this paper is to first evaluate the efficiency of the national anti-corruption campaign and subsequently to understand who the winners and losers are, especially in terms

\footnotetext{
${ }^{1}$ Corruption in this setting refers to the giving of bribes for permission to cheat or for higher scores than deserved.

2 This exam became known in the media as the "Xeroxed exam," referring to the fact that many students were found to have identical test answers including in essay type exams.

${ }^{3}$ Moldova's CCTV surveillance and Cambodia's police presence resulted in $56 \%$ and $26 \%$ of students passing the exam compared with over $94 \%$ and $87 \%$, respectively, in the past.
} 
of students' poverty status. To accomplish our first objective, we evaluate the punishment and monitoring components of the campaign. Starting with the 2011 school year, the punishment side of the campaign comprised threats of dismissals and imprisonment for teachers, while corrupt students, besides being eliminated from the exam, would be suspended from any retakes for over a year. The commitment to punish teachers and students caught red-handed was demonstrated by the high number of trials related to exam fraud immediately after the 2010 Baccalaureate. The installation of CCTV cameras in exam centers, the second component of the campaign, was an additional effort to eradicate mass cheating and fraud. This measure was not announced until May 2011, one month prior to the Baccalaureate exam. Just over half of the counties had video surveillance in 2011, while the rest installed cameras in 2012 when the CCTV surveillance became mandatory. Hence, for the monitoring part of the campaign we have access to quasi experimental variation in camera installation which we utilize in a difference-in-differences (DD) framework, to compare the monitored counties (some in 2011 and all in 2012) with those not monitored (all in 2009-2010 and some in 2011). This yields an estimate of the additional effect of increased monitoring on the high-stakes Baccalaureate scores. While the punishment component was implemented across the country at the same time, because of its strict implementation and using additional placebo tests, we will be able to say something about its impact and its increased effectiveness when combined with monitoring.

Having established that the anti-corruption campaign did have an overall effect in lowering Baccalaureate scores and pass rates, we next investigate who the winners and losers from the campaign are. We analyze the heterogeneous effects of the anti-corruption campaign for the high vs. low income (poor) students to understand how students across the income distribution fare in a more as opposed to less corrupt education system. Given that bribing requires economic resources and is an opportunity to circumvent effort in producing high scores, we hypothesize that eliminating or decreasing corruption in relation to the Baccalaureate would benefit poor students. As the Baccalaureate score is the only (or major) admission criteria for higher education in Romania, we expect our results to carry over to the admission to higher education. To corroborate this finding, we have collected additional data to directly investigate the consequences of the anti-corruption policy for admission to higher education at an elite university.

We provide a number of interesting findings. We find that exam outcomes dropped sharply already in 2011 and that the drop came from both the monitored and non-monitored counties, yet it was larger in the monitored ones. By 2012, the average pass rate had almost 
halved compared with 2009. In the DD analysis we find that the presence of CCTV cameras, in addition to the credible threats of punishment, reduced the Romanian written exam score by $0.21 \mathrm{SD}$, the probability of passing the Baccalaureate by 9.5 percentage points and the overall Baccalaureate score by $0.31 \mathrm{SD}$. The analogous analysis of a low-stakes exam, with no scope for corruption (the oral Romanian exam), reveals neither a general drop in scores in 2011 or 2012, nor a decrease in response to the additional monitoring part of the campaign. We interpret this as suggestive evidence that punishment threats work, and that monitoring increases the effectiveness of the punishment threats. Moreover, we show similar patterns for pass rates at the Baccalaureate exam in Moldova, a country with almost the same educational structure as Romania who was also facing corruption problems and who introduced a very similar policy - harsher punishments in 2012 and CCTV cameras in the examination centers in 2013. From this exercise we conclude that: 1) monitoring and punishment work best when interacted and, more specifically, that monitoring enhances the effectiveness of punishment threats and 2) that our main results are not driven by some other possible changes that happened to occur in Romania around that time.

We also find that the anti-corruption campaign increases the gap in exam outcomes between non-poor and poor students, contradicting our original expectation that fighting corruption should close this score gap. We show that this diverging pattern between poor and non-poor is stable after controlling for ability differences. We discuss possible mechanisms behind this result in section VI.

Finally, we are also able to investigate the consequences of the anti-corruption policy (the additional effect of monitoring) for admission to higher education. Using data from an elite university, we show that the monitoring significantly reduced the chances of admission for poor students, hence confirming most of the results found for the Baccalaureate.

Our paper makes several contributions to the literature on fighting corruption and on the economic consequences of corruption. Economic theory argues that the right combination of increasing the probability of detection (through monitoring) and the threat of punishment may reduce corruption by increasing its costs (Becker and Stigler, 1974). However, evaluation of policies that combine punishment and monitoring has proven to be a challenging task (Hanna et al., 2011; Svensson, 2005). The setting we have for the year 2011 is one where, akin to a Becker-Stigler model of crime, we have a combination of incentives and varying detection probabilities. Counties that installed cameras faced both a stronger incentive (credible punishment threat) and increased monitoring, whereas counties that did not install cameras faced the new punishment threats but no actual increase in monitoring. This allows us to bring 
additional evidence on the interplay between punishment and monitoring and their effects on exam outcomes. Our research therefore complements the literature on anti-corruption policies, which has so far explored monitoring through official audits (Ferraz and Finan, 2008, 2011; Di Tella and Schargrodsky, 2003) and community-based monitoring interventions (Duflo et al., 2012; Reinikka and Svensson, 2004, 2005; Olken, 2007), and has also analyzed changes in incentives (Banerjee et al., 2008; Duflo et al., 2012). Some of these studies shed light on the interplay and relative effectiveness of monitoring and incentives in discouraging dishonest practices. ${ }^{4}$ Our paper offers evidence that monitoring is effective insofar as it enables incentive schemes to operate better, even in the high-stakes setting of a high school exit exams of crucial importance for future education and success in the labor market. The paper also contributes additional evidence of the effectiveness of monitoring to an emerging literature on the role of CCTV cameras in combating crime (Priks, 2014, 2015; King et al. 2008, Welsh and Farringdon, 2009, 2003). ${ }^{5}$

One important contribution of our paper is the estimated impact of fighting corruption on inequality, and in particular inequality of educational opportunity. While social scientists have argued that (income) inequality is positively correlated with the level of corruption (see, e.g., You and Khagram, 2005; Rothstein and Uslaner, 2005), little is known about the distributional consequences of the various means to fight corruption and particularly how curbing corruption influences inequality of opportunity in a society. This is problematic as corruption might adapt and transform to circumvent the new enforcement mechanisms, generating a redistribution of resources and opportunities that could increase inequality and the importance of family income for educational outcomes. Importantly, empirical evidence on the welfare consequences of corruption remains very scarce. ${ }^{6}$ By separating the effects of

\footnotetext{
${ }^{4}$ Nagin et al. (2002) report on a field experiment which showed that decreasing the rate of monitoring observable by employees led them to shirk more, independently of how good their alternatives in the labor market were relative to their job. Di Tella and Schargrodsky (2003) examine the effects of wages and audits during a crackdown on corruption in Buenos Aires hospitals. They find that the wages played no role in reducing corruption (inferred from the drop in previously inflated hospital input prices) when the probability of detection was close to $100 \%$, but only when auditing was less frequent. Duflo et al. (2012) show that monitoring with tamper-proof cameras worked in reducing teacher absenteeism insofar as it was instrumental in implementing an incentivizing attendance-based wage scheme. Their model predicts that at the very least, punishment prospects (fear of dismissal) should put a bound on dishonest behavior. Banerjee et al. (2008) follow the punishment approach of incentives and show that credible threats of punishment (through pay cuts and dismissal) were indispensable in getting government nurses in India to come to work, even when camera monitoring was in place. The impact of changing monitoring or incentives on corruption and shirking linked with the education process is also illustrated in Glewwe et al. (2010).

${ }^{5}$ The effectiveness of CCTV cameras in reducing crime is a current topic, with million dollars being spent in this public safety infrastructure. Priks $(2014,2015)$ document the causal effects of CCTV cameras on unruly behaviour and some types of crime, using temporal variation in CCTV installation in Swedish stadiums and underground. King et al (2008) showed that property crime was reduced as a result of CCTV monitoring on the streets of San Francisco.

${ }^{6}$ Exceptions include Ferraz et al. (2012), who explore variation in corruption in education across Brazilian municipalities, showing how more corruption translates into lower scores for the students, thereby assessing the efficiency costs of corruption, and Choe et al. (2013), who show survey evidence from Bangladesh that corruption in education is most taxing
} 
reducing corruption between low- and high-income students, conditional on ability, we also infer the consequences of corruption on educational opportunity for students from different backgrounds - a perspective previously unexplored. This is important because allocative inefficiencies, for instance in the selection into higher education, can have great consequences for longer-run economic development and economic inequality (Banerjee et al., 2012). Our paper also relates to the large literature on how credit constraints (in this paper in the form of bribes) affect continuation to higher education, especially with regard to selection across the ability and family income distribution (see Lochner and Monge-Naranjo, 2012, for a survey).

The paper is structured as follows. Section I presents the setting and the anti-corruption initiatives. Section II provides the details of our data. Section III provides a graphical analysis of the data. Section IV outlines our empirical strategy. Sections V and VI present our main empirical findings. Section VII presents the effects on admission to university. Our conclusions are presented in Section VIII.

\section{Background}

\section{A. The Romanian education system}

The Romanian pre-university education starts with elementary school, which is divided into primary school ( $1^{\text {st }}$ to $4^{\text {th }}$ grade) and secondary school, or gymnasium $\left(5^{\text {th }}\right.$ to $8^{\text {th }}$ grade $)$. Upon graduation from secondary school, at the end of $8^{\text {th }}$ grade, the students need to pass a national standardized exam. The score from this exam and the student's graduation grade point average $\left(5^{\text {th }}\right.$ to $8^{\text {th }}$ grade) contribute with equal weights to the student's tertiary or high school admission grade. Based on this score and a comprehensive list of ranked high schools, the student is systematically allocated by the Ministry of Education (through a computerized, transparent allocation procedure) to a high school and a specific track at that school: i) a theoretical track, which includes humanities and sciences, ${ }^{7}$ ii) a technological track, which includes technical training, services, and natural resource- and environment protectionoriented education, or iii) a vocational track, which includes arts, military, theology, sports and teaching (for more details on the allocation, see Pop-Eleches and Urquiola, 2013).

Upon completion of high school, students take the Baccalaureate exam. This highstakes nationwide standardized test is mandatory in order to obtain a tertiary education degree. Admissions to university or further training as well as access to the labor market are

for the poor and less educated. Similarly, Hunt (2007) shows evidence from Peru that the victims of misfortune (crime) are also more likely to be victims of bribery.

${ }^{7}$ The theoretical track is typically the most popular among high-ability students. 
almost exclusively based on this test. ${ }^{8}$ The exam takes place every year in June and consists of a few oral and written standardized tests, with slight alterations across years. ${ }^{9}$ Until 2013 , the tests within each subject may have had different degrees of difficulties across tracks, but they were standard within the same track. The only exception was the written exam in Romanian language and literature, which was identical for all students regardless of track, while its format has remained unchanged over the years.

\section{B. The Baccalaureate and the Anti-corruption Campaign}

The pressure of passing the Baccalaureate exam (with high scores) has been constantly rising since about 2002. It was around then that the increase in the number of private universities and the introduction of tuition fees in public higher education began. This made the university admission exams less relevant as the Baccalaureate scores attained increasing shares in the admission criteria (up to 100\%), raising the stakes of the high school exit exam. The combination of the high stakes and poor remuneration of public school teachers created an endemic corruption environment surrounding the Baccalaureate exam, as also documented by Borcan, Lindahl and Mitrut (2014). ${ }^{10}$

The unofficial payments behind the Baccalaureate exam can be summarized as follows: ${ }^{11}$ i) Collective bribes which are funds collected from the students a few days ahead, or just before the exam. These are voluntary but very common, usually perceived as a norm by all students and are used to "grease the wheels" ("protocol" - meals, money or small gifts for the exam committee) or directly given to the exam surveillance committee and proctors to turn a blind eye or even help in-class cheating. Because these bribes affect what happens during the exam, it is this type of corruption ("pay to cheat") that the CCTV monitoring can reduce. ii) Individual bribes, which are large sums transferred privately by the more affluent students to members of the exam evaluation committee to increase the student's score, or to replace the exam paper with a correct version. This is usually done with the help of a student's teacher or school principal who act as intermediaries for the bribe transfers. The corruption trials following the 2010 exam illustrate this form of bribing: "The defendant

\footnotetext{
${ }^{8}$ All tests throughout school are scored on a scale from 1 to 10 , and to pass a student must obtain a minimum score of 5 on each test. To pass the Baccalaureate a student needs at least 5 on each exam and a minimum overall average score of 6 .

${ }^{9}$ The most important changes were the exclusion of oral tests from the overall score starting in 2010 and the elimination of the fourth written test. All these tests displayed abnormal score distributions highly concentrated at the top marks.

${ }^{10}$ A 2003 World Bank Report on corruption in Romania reveals that more than 67\% of the respondents alleged that all or almost all public officials in Romania are corrupt, while more than $50 \%$ of the respondents believed that bribery is part of the everyday life in Romania. The figure was particularly high for the education and health systems, as up to $66 \%$ of the respondents confirmed that they were paying the so-called atentie (unofficial payments or bribes). According to the Global Corruption Barometer from Transparency International, in Romania in 2010/2011, 37\% of respondents believed the education system was corrupt or extremely corrupt, which was above the world average.

${ }^{11}$ This distinction is based on examples of bribes documented in the court cases and official press releases of the National Anticorruption Directorate (retrieved from www.pna.ro- in Romanian).
} 
[school principal, name] claimed and received from the defendant [name] the total amount of 7.000 RON [680 EUR], which she then transferred to the defendant [name]. This money was received in order for the latter, as examiner in Romanian language, to give higher scores to the (contributing) candidate" (DNA release No. 473/VIII/3, 2010). ${ }^{12}$ Thus, while punishment threats may affect the incidence of individual bribes, CCTV monitoring cannot capture these private deals. The fact that the pass rates of 80-90\% until 2009 did not reflect ability but rather mass fraud was common knowledge among teachers, principals, parents, and students. ${ }^{13}$

Following the 2010 Baccalaureate, which was marked by a surge in grade-inflating corruption generated by the $25 \%$ public sector wage cut in May 2010, a high number of teachers were brought to trial on allegations of selling grades. In response to this scandal, the Ministry of Education started a Baccalaureate "cleaning" campaign in 2011. In a first step, the Ministry publicly appealed to all schools and teachers involved in the exam to better enforce the examination rules and threatened to punish teachers caught receiving bribes with a pay cut and/or prison time, ${ }^{14}$ while also promoting a zero tolerance policy against collective bribes. Additionally, a new rule stipulated that other parties (parents, NGOs) had the right to enroll as exam proctors to increase transparency. In terms of harsher punishments, the new rules also stipulated that students caught cheating would be banned from retaking the exam for at least one year. On top of these measures, there was a recommendation to organize the exam, when possible, in centers equipped with surveillance cameras. The introduction of CCTV cameras was reinforced in May 2011 through public appeals by the Ministry of Education to the county inspectorates to comply with this recommendation. However, because the request was not binding, each of the 42 county inspectorates decided independently whether or not to install CCTV cameras in the examination centers by the end of May. ${ }^{15}$ As a result, 25 counties had cameras installed in the examination centers and 17 did not, blaming the lack of funds. Where installed, the cameras were placed in the front of the room and on the hallways, and

\footnotetext{
${ }^{12}$ Another example from the National Anticorruption Directorate (DNA): "Around the time of the Baccalaureate exam, June 2010, in the exam center [name], the defendants [name] - principal, [name] - deputy principal, [name] - secretary and [name] - teacher, [...] have [...] planned and organized a fraudulent exam, in which students who paid various amounts of money passed the tests. [...] On June 28, 2010, after the written Romanian exam, upon a police search of the high school premises, 56 envelopes containing money and the names of the students [who have contributed] have been identified. In total 91.850 RON (equivalent to 21,360 EUR) and 7,750 EUR have been found. In addition, [the principals] have received 19,000 RON , 1,850 EUR and 8 envelopes containing unspecified amounts from students interested in passing the exam." Press release No. 633/VIII/3, 2010.

${ }^{13}$ For a more detailed treatment of the state of corruption in Romania, particularly in the education system, see Borcan, Lindahl, and Mitrut (2014). Based on PISA test scores, the authors also document the strong contrast between national exam scores and true ability compared with other European countries.

${ }^{14}$ Threats ranged in severity from being excluded from the examination for a few years to going to prison (following the 2010 example).

${ }^{15}$ Metodologia de organizare si desfasurare a examenului de bacalaureat, 2011, Annex 2 of the Ministry of Education's Decision no. 4799/31.08.2010, concerning the organization of the Baccalaureate exam.
} 
the camera footage was collected and screened by the county inspectorates. Table A1 in the online Appendix A confirms that the counties that did not install CCTV cameras in 2011 were on average poorer than the others. We return to this county self-selection later.

Thus, in 2011, counties that installed cameras faced both a credible punishment threat and increased monitoring, while non-implementers faced a credible punishment threat but no actual additional monitoring.

The gradual introduction of monitoring allows us to compare education outcomes in a corrupt (in 2011 in non-monitored counties and before 2011 in all counties) and a non- (or less) corrupt system (in 2011 in monitored counties and in 2012 in all counties). This variation sets the foundation for our empirical strategy, as described in Section III.

\section{Data}

For the purpose of our main empirical investigation we employ several datasets:

i) Administrative data provided by the Ministry of Education and covering the universe of students enrolled at the Baccalaureate exam (typically close to 200,000 students every year) from 2009 to 2012. From this source we retrieve each student's exam outcome (scores and whether the student passed or not), track (theoretical, technological or vocational), date of birth, gender, and the county, locality, and school of enrollment. ${ }^{16}$ For a subset (around 70\%) of students we also have administrative data on the student's average scores in middle school $\left(5^{\text {th }}-8^{\text {th }}\right.$ grade $)$, which we use as a proxy control for ability. ${ }^{17}$

ii) Because the administrative data does not cover student poverty status, we construct this measure from individual information on the students eligible for the Money for High School (MHS) public program of financial assistance for high school students from poor households. A student was eligible if the gross monthly income per household member was not higher than 150 RON (45USD) in the 3 months prior to applying (which is about equivalent to the $15^{\text {th }}$ percentile of the national household income per household member). The MHS data contains information on all eligible students for each year when they submitted an application. Thus, in our main analysis we can build the full MHS eligibility history (throughout high school) for all students taking the Baccalaureate between 2009 and

\footnotetext{
${ }^{16}$ It is for these years (2009-2012) that we have the most reliable data on students' poverty status (see below) and their ability proxy (the middle school scores for the cohort entering high school in 2004 have a lot of missing information). We do, however, use earlier Baccalaureate data for some sensitivity analysis.

${ }^{17}$ This measure has been recently used in other papers (see Pop-Eleches and Urquiola, 2013). Unlike the Baccalaureate, this is not a high stakes score, because, while it is used to determine admission into high school, all students in Romania ultimately receive a place in high school, which diminishes, but does not completely eliminate the incentives to inflate this grade through corruption.
} 
2012. ${ }^{18}$ In particular, we create an indicator for poor students equal to 1 if the student has been found in the pool of eligible applicants at least one year during high school. For further discussions, please see the online Appendix B.

When we merge the datasets i) and ii), and we exclude exam retakes (instances where students retake the exam again in different years), we obtain our working sample of 731,505 students. ${ }^{19}$ Additionally, in an attempt to understand the allocation of students to university studies following the anti-corruption campaign, we will merge this data with individual data from the admission to a top Romanian university from 2009 to 2012, generating a sample of 15,821 students. We discuss this data when we address this issue later in the paper.

Table 1 outlines some key statistics for our main variables, separately by year. The Romanian language written exam scores (the test most amenable to comparison, as it is identical for all students and similar across years) declined from an average of 6.81 in 2009 and 7.02 in 2010 to 6.15 in 2011 and 2012. ${ }^{20}$ The overall Baccalaureate pass rate dropped from $81.3 \%$ in 2009 to $48.2 \%$ in 2011 and 2012. This is reflected in the decline of the overall Baccalaureate score. It is important to note the drop in the 2010 pass rates and overall exam scores, in relation to 2009, in spite of the increase in corruption until 2010 (see also Figure 1). The main explanation behind this fall, as also supported by the 2010 official report from the Ministry of Education and Borcan, Lindahl, and Mitrut (2014), lies in a few, but important changes in the exam structure: $a$ ) The oral Romanian exam, compulsory for all students, was rendered irrelevant to the calculation of the overall Baccalaureate grade (and passing). Before $2010,99 \%$ of the students passed this exam (a minimum grade of 5), with an abnormally high $50 \%$ share of the students receiving scores between 9 and 10 (out of 10). b) One elective exam was removed in 2010 (before this year around $75 \%$ of the students chose physical education for this elective test and of these, more than $90 \%$ scored a maximum score of 10) (see the online Appendix B, Figures B1.c and B1.d). The Romanian language written exam

\footnotetext{
${ }^{18}$ The MHS funds (a monthly allowance of 180 RON ( 53USD) per student) have been disbursed every year since 2004 and a student could reapply at the beginning of every school year. However, in the first years of the program the vast majority of applicants were in the $9^{\text {th }}$ or $10^{\text {th }}$ grade (the $12^{\text {th }}$ grade students applying started at a low $10 \%$ ). The first cohort that had the possibility to apply for the MHS financial assistance from grades 9 to 12 (the entire high school) is the one graduating in 2009. We do report our analyses based on the 2006-2012 data as a robustness check in the online Appendix B, Tables B4 and B5.

${ }^{19}$ For each student we keep only the first year when the student took the exam, because we are interested in campaign impact the first time the students take the exam, clean of other behavioral responses like further study. Moreover, there are disproportionately many students that fail repeatedly and re-take the exam after the anti-corruption campaign. The results are very similar when we include the exam retakes. In addition, this sample also excludes $2 \%$ of the student population, for which we do not have data on our set of controls.

${ }^{20}$ The increase in 2010 is discussed in Borcan, Lindahl, and Mitrut (2014) to be a direct consequence of the 2010 public sector austerity measures and the sudden increase in corruption related to the Baccalaureate.
} 
remains the most reliable outcome, but we also report the passing rate and overall score results. We show sensitivity tests excluding the year 2010 and using 2009 as the baseline year.

Table 1 also shows that the share of poor students (as proxied by the MHS eligibility status) increases slightly over time, which is concomitant with a decrease in sample size. The 20\% drop in sample size in 2012 is most likely due to fewer students enrolling at the Baccalaureate. ${ }^{21}$ The table also reflects changes in the student composition over time along other dimensions (gender, track, rural school), which we control for in the estimations below. These changes should be unproblematic as we show them to be proportionally very similar in counties that installed camera in 2011 and those that installed in 2012 (see Table A1 in the online Appendix A). We discuss the student dropout issue in the sensitivity analysis.

\section{Graphical Evidence}

We start with an illustration of the evolution of exam outcomes over time in Figures 1 and 2. These figures summarize the essence of our findings. Figure 1 shows the 2004-2012 written Romanian score, pass rate, and overall exam score averages, separately for counties that installed cameras in 2011 (early installers) and those that installed cameras in 2012 (late installers). The notable patterns are: 1) in both early and late implementers, the Romanian written scores and the overall pass rates dropped quite sharply in 2011, suggesting that the anti-corruption campaign as a whole was effective in both types of counties and that the threats of punishment played the largest role; 2) the drop in performance in early implementer counties is larger in 2011 than in late implementer counties, suggesting that monitoring had an added effect in reducing corruption; 3) while early implementation increases somewhat the performance levels in 2012 relative to 2011, the score in late implementation counties continue to drop in 2012 , reaching levels below or similar to the early implementers. ${ }^{22}$ ) the later installers were, on average, better off before 2010 and we observe parallel trends before 2011 in early and late implementers for average pass rates but the trends converge somewhat for the written Romanian score. We discuss issues of selection into camera treatment in the identification section below; ${ }^{23}$ and 5) the clear drop in pass rates and overall exam scores which occurred already in 2010 because of changes that made the exam harder to pass (some

\footnotetext{
${ }^{21}$ To account for this, we run robustness tests, including in our main specifications the share of Baccalaureate enrolled to high school enrolled students (four years prior the Baccalaureate) and the results are unaffected (online Appendix Table A4). ${ }^{22}$ The small increase in scores for the early implementers in 2012 relative to 2011 could be the effect of different factors (e.g., an increase in students' and/or parents' effort). We will discuss this in the Mechanism section.

${ }^{23}$ We also note that the score for the late implementers continued to drop in 2012, when the objective monitoring was introduced and were reaching levels below the early implementers, even though the late implementers had higher scores in 2010, something which also may indicates that the late and early implementers may differ along some characteristics and therefore suggesting the need to account for self-selection into treatment.
} 
tests with nearly guaranteed top scores were removed from the calculation of the overall exam score), as discussed above.

These patterns are perfectly preserved in Figure 2, which displays the evolution of exam outcomes from 2006 to 2012, separated by poverty status. ${ }^{24}$ However, there is a notable contrast between poor and non-poor students. The score dip associated with camera monitoring in 2011 is larger for the already worse-off poor students. The pattern observed is that the dispersion in exam outcomes between poor and non-poor students increased, and the poor did even worse after their introduction.

\section{Estimation strategy}

To assess more formally the impact of corruption-fighting measures on exam outcomes, we employ a difference-in-differences (DD) strategy. In particular, we use the variation between counties and over time in the installation of CCTV cameras to separate out the additional effect of monitoring from the effect of harsher punishments captured by the 2011 and 2012 year indicators. The general specification is:

$$
y_{i c t}=\alpha+\beta T_{c t}+\gamma^{\prime} X_{i c t}+\varphi_{t}+\theta_{c}+\theta_{c} \cdot t+\varepsilon_{i c t}
$$

where $i$ indexes a student attending a school in county $c$ in year $t . y_{i c t}$ is one of our three main outcomes of interest: 1) the score on the standardized written Romanian language exam, 2) an indicator equal to 1 if the student passed the Baccalaureate exam and 0 otherwise, and 3) the score on the overall Baccalaureate exam; $T_{c t}$ is our main variable of interest, an indicator equal to 1 if the student is CCTV monitored (for all counties in 2012 and for 25 out of 42 counties in 2011) and 0 otherwise; $X_{\text {ict }}$ includes indicators for whether the student comes from a poor family, for gender, for school track and for rural area (and in some robustness checks, on a smaller sample, an indicator whether the student had below median $5^{\text {th }}-8^{\text {th }}$ grade score, which is our ability proxy). These indicators are included in order to control for compositional sample changes over time across treatment and control; $\varphi_{t}$ includes year indicators; $\theta_{c}$ includes 41 county indicators and $\theta_{c} \cdot t$ are county indicators interacted with a linear time trend. In some of the estimations we replace the county indicators with a full set of school or family indicators. In all regressions we cluster the standard errors at the county level, since the treatment implementation is county-wide (resulting in 42 clusters). We also estimate specifications where we allow all coefficients vary across students based on whether

\footnotetext{
${ }^{24}$ Noting that the poverty proxy is less reliable before 2009.
} 
they are classified as poor or non-poor (and by their ability and gender, which we report in the online Appendix B).

The DD estimate, $\hat{\beta}$, will capture the additional impact of CCTV installation on exam scores based on the variation in exam outcomes within counties over time (after vs. before camera installation). Since no county had cameras installed in 2009-2010 and some counties installed them in 2011 and the rest in 2012, this estimate will be a weighted average of the exam score effects for those installing cameras in 2011 and 2012, respectively. ${ }^{25}$

The 2011 and 2012 year coefficients are also of interest since they capture the shift in exam outcomes relative to earlier years, net of the impact of installed cameras. However, these indicators can be interpreted causally only under the very strong assumption that the sole source of variation in exam outcomes 2011-2012 relative to before is due to the corruption-fighting campaign. This is obviously a restrictive assumption as a number of other factors might have changed across years, e.g., different changes as a result of the overall economic situation. To investigate the plausibility of this assumption, we estimate equation (1) using as outcome the scores from the low-stakes oral Romanian exam. This exam is also part of the Baccalaureate and covers the same topics as our main outcome, i.e., the written exam, but does not count towards the overall grade and there is consequently no scope for corruption. Hence, in our model using performance on this exam as the dependent variable in estimation of equation (1), the year indicators' coefficients can be read as "pure" year effects. If the estimates for the year indicators and the DD indicator are zero for the oral exam, we believe we can make a reasonably strong argument for an interpretation of the year indicators for the other exam outcomes as saying something about the overall impact of punishment threats. This is especially likely since the changes in exam scores are so large it would be unlikely to find other factors that could explain this whole shift in scores using an exam that is comparable across years. Yet, we need to be cautious when interpreting the year effects as effects of the anti-corruption policy (see Section V.B below). Similarly, when we estimate equation (1) separately by poor and non-poor students, we focus on comparing the resulting estimates across these groups. The identifying assumption is then that there are no other factors that could explain this diverging pattern.

Finally, the question of self-selection of counties into the CCTV monitoring treatment warrants some discussion. Since the CCTV surveillance was not enforced in 2011, county

\footnotetext{
${ }^{25}$ In this specification we are implicitly assuming that the 1-year post effect is the same as the 2-year post effect. We will show in our sensitivity analysis (online Appendix A) that the results are very similar when we do not include year 2012.
} 
inspectorates had the final decision on the matter. The choice not to install cameras was typically motivated by lack of funds. Thus, any claim of random assignment into camera treatment would be untenable in this context. To learn more about the selection into exam monitoring, we look at the mean differences in outcomes and controls between early and late installers in the pre-reform years 2009-2010 (online Appendix B, Table B1). We learn that students' ability or performance does not differ across counties, and neither does our surveybased proxy for corruption norms, although counties that installed cameras late are marginally more trusting in the justice system. ${ }^{26}$ Yet, on average, early installing counties seem to have significantly fewer poor students and to be slightly larger. As online Appendix A, Table A1 shows, and as is also evident from Figure 2, the poor students' shares sustain a proportionally similar decrease in early and late installing counties. These facts support the official justifications and also reassure us that the factors affecting the monitoring decision are accounted for in our baseline regressions. Under the assumption that county fixed effects and county-specific time trends account for any unobserved county-level characteristics related to the camera decision, poverty, and the observed exam outcomes, the DD estimator yields the causal impact of the CCTV monitoring on exam outcomes, from estimations using either the full sample or the samples divided by poverty.

\section{Estimation Results of the Overall Impact of the Anti-Corruption Campaign}

Given the graphical evidence above, we start this section by further assessing the impact of the corruption-fighting campaign and in particular we aim to understand the contribution of each of the campaign mechanisms - monitoring and increased threat of punishment. Next, we inquire about who benefits and who loses from curbing corruption by looking at the heterogeneous campaign effects for poor vs. non-poor students (in Section VI). Additionally, we attempt to understand whether the anti-corruption campaign significantly changed the composition of students admitted at an elite university (Section VII).

\section{A. The effect of installing CCTV cameras}

Table 2 presents results from estimating equation (1) for the scores on the written Romanian exam, a standardized test that has the same structure across years and tracks

\footnotetext{
${ }^{26}$ We compute a proxy based on the share of people having an informal network, at the county level, using the answers to a question from the 2007 Romanian Barometer of Public Opinion: "Is there anyone (i.e., informal network) that could "help" you solve (i.e., informally): issues in court/trials, medical problems, city hall, police, or issues related to the local authorities.". We compute a proxy for the level of confidence in justice, based on perceived trustworthiness of the justice courts, elicited in the same survey.
} 
(columns 1-4), for the probability of passing the Baccalaureate exam (columns 5-8) and for the overall Baccalaureate score (columns 9-12). In columns (1), (5) and (9) we only include the year indicators (the base is 2010) and county indicators. In columns (2), (6) and (10) we add the CCTV monitor indicator. In columns (3), (7) and (11), we add the controls described above and in columns (4), (8) and (12) we also include county specific linear trends. We note that in the latter columns the estimates for the year indicators are slightly smaller in magnitude, but not straightforward to interpret due to the interactions between county fixed effects and yearly trends. ${ }^{27}$

In column (1) we show that the scores on the written Romanian exam decreased sharply in 2011 and 2012 relative to 2010, which is in line with the graphical evidence in Section III. $^{28}$ The drop is equivalent to around half of a standard deviation. We also note that there is no further drop in 2012, compared to 2011. This is in line with Figure 1, where we observe a further drop for those counties installing cameras in 2012, but a slight increase in the counties that did install cameras in 2011. In column (2) we also add the camera indicator in an attempt to tease out the additional effect of increased monitoring. We argue that, in this specification, the two post-campaign year indicators are likely to capture the impact of the threats of punishment on the written Romanian exam (something we return to below). We then see that the written Romanian score decreases by about 0.246 points due to CCTV monitoring, almost $30 \%$ of the overall drop in scores. Adding further controls (column 3) does not change the estimates. However, when we add, in our preferred specification, the county specific yearly trends (column 4) the CCTV camera magnitude becomes larger (-0.353 points), equivalent to a $0.21 \mathrm{SD}$ decrease in scores on the Romanian exam relative to the sample mean (using the SD from 2010), explaining about $40 \%$ of the overall observed drop in scores between 2010 and 2012. Albeit their statistical significance does not change and their magnitude slightly drops, here we do not show the estimates for the year indicators since their interpretation is no longer straightforward.

For the probability of passing the Baccalaureate exam and the overall Baccalaureate score, the main results show a similar pattern as for the written Romanian exam. In particular, the impact of CCTV camera monitoring lowered the probability of passing the Baccalaureate by around 9.5 percentage points and lowered the overall Baccalaureate scores by 0.512 points

\footnotetext{
${ }^{27}$ The county - yearly trends interactions will absorb some of the overall year effects and the remaining year indicator coefficients will reflect the time effects in the baseline county left out.

${ }^{28}$ One apparent surprising result is the negative coefficient of the 2009 indicator for the written Romanian exam score. The reason for this pattern is the escalading corruption in relation to the Baccalaureate grades, which, especially for the written Romanian exam, peaked with the 2010 exam following a 25\% wage cut for all public school educators. We show these results in Borcan, Lindahl, and Mitrut (2014).
} 
(0.31 SD decrease relative to the sample mean). We also note that, relative to 2010, the 2011 and 2012 year indicators clearly exhibit much lower values. Yet, at this point it is difficult to assess whether these negative coefficients indicate a response to punishment threat or some other changes. We provide details on the effect of the punishment threat on exam outcomes in the next subsection. ${ }^{29}$

There are several concerns related to whether the CCTV monitoring in Table 2 above can indeed be interpreted as the additional effect of the monitoring component of the campaign. In particular, the negative impact of monitoring on test scores may reflect not only corruption fighting per se but (also) test anxiety from the newly introduced CCTV cameras. While we cannot fully dismiss this possibility, we believe that anxiety from monitoring would not account for such a large drop in scores. In the same line, Bertoni et al. (2013) show that the negative impact of the presence of an external examiner on test scores is due to reduced cheating rather than to anxiety. Moreover, the evidence from the psychology literature (Chapell et al., 2005) indicates that females display higher levels of anxiety during tests than males, while we will show in the heterogeneity analysis in the online Appendix B (Tables B6 and B7) that males perform worse compared with females following the campaign.

We also address some additional concerns which, for space considerations, are reported and discussed in more detail in the online Appendix A. In particular we show that our results remain unchanged when: i) varying the number of years in the sample by adding more pre policy years, to control more adequately for pre-existing trends (Table A2); ${ }^{30}$ ii) adding a placebo camera indicator, introducing tighter controls such as school and family fixed effects, excluding year 2010 (due to concerns about high corruption as a result of the wage cut policy) and excluding the year 2012 (Table A3); iii) adding a control for ability differences (for a subsample where this information is available) (Table A4); iv) checking for composition changes due to dropout rates as a response to the campaign (Table A4); v) matching counties by observable characteristics (Table A5).

Overall, our results seem to indicate that monitoring lowered the exam scores, most likely as a result of reduced ability to engage in petty and mass in-class cheating in exchange

\footnotetext{
${ }^{29}$ We also note that the 2009 year indicator is positive when we look at the probability of passing the overall exam. This is because the probability of passing drops already in 2010 due to additional changes in the exam structure/passing requirements as discussed in Section II.

${ }^{30}$ We choose not to include more pre-years in our main analysis because we do not have reliable information for some important variables such as poor before 2009 (see section II). Moreover, as mentioned previously, we are implicitly assuming that the 1-year post effect is the same as the 2-year post effect we would like to include more post-reform years (2013 and 2014). However, this is not possible because, following the dramatic decrease in the pass rates in 2011 and 2012, the Ministry of Education made the Baccalaureate exam different for each track and sub-track in accordance with the different instruction times (for instance humanities students have more instruction hours in Romanian literature than science students), making this test less comparable after 2012.
} 
for collective bribes paid to the exam committee members. Yet, we cannot fully exclude that, even in the presence of CCTV monitoring, some students would resort to individual bribes (before/after the exam takes place). We will return to this point when we discuss the mechanisms in section VI. In the subsections below we bring further evidence that the estimated reduction in scores is indeed due to a reduction in corruption owing to the punishments and the added effect of monitoring.

\section{B. Can we separate out the punishment from the overall effect of the campaign?}

\section{Evidence from using a low-stakes exam}

While in the analyses above we have shown that the monitoring part of the campaign had an added impact on curbing corruption, interpreting the year indicators as the effects of the threat of punishment (net of camera monitoring) is much more problematic. To convincingly establish that the retake restrictions and the threats of prosecution for teachers and students were credible enough to reduce corruption, we would ideally like to contrast the year effects in the written exam regressions with those from a no or low stakes exam with no scope for fraud and thus presumably no impact of the anti-corruption campaign. This test would be more compelling if this exam's intrinsic features were similar to the high-stakes exam that it is compared against. Conveniently, the Romanian language is tested both via an oral and a written exam during the Baccalaureate, both covering the same topics. ${ }^{31}$ However, since 2010, the oral exam has been made irrelevant for the calculation of the overall Baccalaureate score and converted to an objective aptitude test, which students cannot fail (given that they are present at the exam) but in which they can qualify as an "excellent," "good," or "sufficient" language user (performance levels are marked by a score of 3,2, and 1, respectively). These oral test scores are not required for university admission and do not condition passing (or the grade of) the Baccalaureate, which makes this a low-stakes exam. ${ }^{32}$ As the same skills are required for the two exams but the written one is a high-stakes while the oral is not, the oral exam is the ideal placebo test described above. To make the Romanian written and oral exams comparable we start by translating the latter exam scores, available only on a non-cardinal scale, into percentile ranks using the data from $2010-2012 .{ }^{33}$ Next, we standardize both the

\footnotetext{
${ }^{31}$ The oral Romanian language exam typically takes place one week before the written one. Because the oral Romanian exam is a low-stake exam, the use of CCTV cameras was optional (even in 2012), and actually very few schools monitored this exam. We do not know which schools had CCTV cameras during the oral Romanian exam.

${ }^{32}$ This has been publicly confirmed by school inspectors and teachers. See, e.g. (in Romanian) www.comisarul.ro/diverse/competentele-de-la-bac-valoreaza-zero-barat!_467712.html

${ }^{33}$ We use percentile ranks since the oral exam is expressed on an ordinal scale. This is a useful transformation because if, for instance, the distribution of scores is such that there are relatively few students with a level 3 score, then these students get a
} 
percentile rank oral Romanian scores and the written Romanian scores (by their mean and standard deviation in 2010) for the 2010-2012 cohorts.

We report the results from this exercise in Table 3 which has a similar structure to Table 2. In columns (1)-(4) we show results for the written Romanian exam and in columns (5)-(8) for the oral Romanian exam, both standardized with respect to 2010. Hence, the magnitude of the estimates reported here (columns 1-4) is not directly comparable to those in (columns 1-4) of Table 2 .

Columns (1) and (5) show results from the simple specification with two indicator variables for the two post campaign years. ${ }^{34}$ If we compare the estimates in columns (1) and (5), we see that the scores on the written Romanian exam decreased sharply in 2011 and 2012 relative to 2010, while for the oral exam not only do the 2011 and 2012 indicators have the opposite sign, but they are also much smaller in magnitude than those for the written exam, confirming that performance was not negatively affected by a general year trend; if anything, scores may have actually increased (due to e.g., increase in effort, drop-outs), in which case the 2011 effect for the written exam may be underestimated. This, in turn, suggests that the impact of the overall campaign in curbing corruption is real.

In columns (2) and (6) we also add the camera indicator. In these specifications, we argue that the two post-campaign year indicators capture the impact of the threats of punishment for the Romanian exam. In column (2) we see that the camera monitoring's added effect did make up a non-trivial part, about 35\%, of the overall campaign effect whereas this estimate is statistically insignificant and very small when we look at the oral exam. These results are clearly confirmed if we compare estimates in columns (3) and (4) with those in columns (7) and (8).

One limitation of the comparison between these high-stakes and low-stakes tests is that, even though they cover the same material, students' incentives to invest effort, or their anxiety levels, might differ between these exams. However, in 2011 and 2012 the oral exam took place just one week before the written, which improves their comparability. ${ }^{35}$ Overall, these results lend support to our hypotheses that: 1) the increased threat of punishment brought by the campaign has curbed corruption, as seen in the drop in scores for both the

higher rank score. Note also that, since we also want to compare the estimates for the year indicators, we rank the scores using all three years combined.

${ }^{34}$ We experimented with a regression discontinuity design using birth months as running variable, hence just adding month of birth to a modified specification with an After2011 indicator (for the 2011 and 2012 year dummies). However, the sensitivity analysis revealed problems with endogenous location around the cutoff due to a very non-strict rule of when during the year a pupil could start school.

${ }^{35}$ Even though the oral Romanian exam does not count for students' Baccalaureate (or university) success, one may still think that for some students this is important given that e.g., the other students may see the grade. This is why we consider it a low- and not a no-stakes exam. 
monitored and non-monitored counties; 2) monitoring enhances the effect of the threat of punishment, as seen in the additional score drop when cameras are installed. However, it is important to note that we cannot fully dismiss an indirect impact of monitoring even for the non-monitored counties as they may have also perceived a higher risk of detection. ${ }^{36}$ Finally, we can conclude that indeed, the campaign was more effective when the probability of detection was higher, in the presence of CCTV monitoring.

\section{Additional evidence on the effectiveness of punishment combined with monitoring on curbing corruption: Evidence from a similar policy in Moldova}

Theory and a few empirical studies suggest that increasing the probability of detection is unlikely to work without increasing the costs of being detected, and equally, punishment is ineffective if the chances it will be applied are very low. The setup we have does not allow us to study the effect of punishment in the complete absence of monitoring (due to the possible indirect effect of the monitoring in the non-monitored counties even in 2011) or where monitoring increases in the complete absence of punishment threats. To offer additional evidence that punishment is most effective if combined with monitoring, we take advantage of a similar policy in Moldova, a neighbor country with a very similar education system as Romania, ${ }^{37}$ facing similar corruption problems in connection with the high-stake Baccalaureate exam. Encouraged by the Romanian anti-corruption policy, a crackdown on Baccalaureate corruption in Moldova started in 2012, when the Ministry of Education obliged students to sign a commitment document just before the exam declaring that they are free of any cheating aids (mobile phones, books) during the exam and if caught with any cheating aids they would be banned from the exam for at least a year, regardless of whether they used the aid or not. If caught taking bribes or letting the students cheat, teachers would also be punished. ${ }^{38}$ In addition to these punishment threats, a new methodology prescribed mandatory installation of CCTV cameras in all exam centers in 2013. ${ }^{39}$ This roll-out gives us the opportunity to contrast the Romanian and Moldavian Baccalaureates to understand the effectiveness of punishment threats in the absence of camera monitoring.

\footnotetext{
${ }^{36}$ Since agents' behavior responds to perceived monitoring, which does not necessarily coincide with objective monitoring (Nagin et al., 2002), we cannot exclude that the expected detection probability increased also in non-implementing counties, but to a lower extent.

${ }^{37}$ In Moldova more than $76 \%$ of the population speaks Romanian as their native language, and the Baccalaureate, which is very similar to the one in Romania, includes also a Romanian language written test.

38 There was no clear rule but the methodology stipulated that the punishment would be according to the Moldavian Labor Code. In addition, in 2012 the methodology introduced a recommendation to install CCTV cameras, but this recommendation was not followed ("The video cameras may be introduced in exam centers"). (Source: The Baccalaureate Methodology for the organization of the 2012 Baccalaureate exam, section IV, article 50.)

${ }^{39}$ The Baccalaureate Methodology for the organization of the 2013 Baccalaureate exam, section IV, article 48.
} 
Figure 3 shows a comparison of the evolution of Romanian written exam scores and the Baccalaureate pass rates in the two countries from 2007 to $2014 .{ }^{40}$ Before the campaign, the pass rates were very high (above 90\% in Moldova and 80\% in Romania). Following the 2012 punishment threat campaign in Moldova the pass rates suffered a mild drop to $88.3 \%$. When Moldova introduced the mandatory CCTV monitoring in 2013 the pass rates reached $68.3 \%$ suggesting that indeed the punishment threat worked best when monitoring was also in place. Yet, the threat of punishment in Moldova was not as credible as in Romania (due to the unprecedentedly high number of trials in connection to the 2010 "Xeroxed" exam). Overall, this graphical evidence suggests that the intended effects of the anti-corruption campaign were felt in both countries when a high level of monitoring coupled with punishment was reached (in 2011 and 2012 in Romania and in 2013 in Moldova).

We conclude that monitoring and punishment work best when interacted and, more specifically, that monitoring enhances the effectiveness of punishment threats.

\section{Estimation Results of the Heterogeneous Effects of the Anti-Corruption Campaign}

After having established that the campaign had a drastic effect on the Baccalaureate highstake exam for the average student, in this section we focus on the distributional effects of curbing corruption. In particular, we look at the heterogeneous impact for students who differ in poverty level and investigate some of the mechanisms behind the estimated effects.

\section{A. Heterogeneous Effects Estimates}

We already saw from the evolution of scores in Figure 2 that the poor students seemed to be the most affected group by the camera policy. To lend additional credibility to these findings we now turn to a regression analysis using the DD approach as specified in equation (1), but allowing all coefficients (including the county fixed effects and the county specific linear trends) to differ for poor and non-poor students. These results are presented in Table 4. To save space, we only show estimates of the main effects for the camera and when camera is interacted with the poor indicator. ${ }^{41}$ In columns (1), (4) and (7) we show estimates for the full sample. From column (1) we observe that, as a result of the monitoring policy, poor students' test scores decreased over $60 \%$ more than for non-poor students, and the difference is statistically significant. The decrease for poor students (-0.515) amounts to an impact of about 0.31 SD. Similarly, for the other two outcomes the camera impact is always (statistically

\footnotetext{
${ }^{40}$ For Moldova the data is available only in the form of aggregate figures by year for the Romanian written exam scores and pass rates.

${ }^{41}$ The table with the full set of results is available upon request.
} 
significantly) larger for the poor than for the non-poor students: the Baccalaureate pass rates dropped $14.3 \%$ for the poor (compared to $8.1 \%$ for non-poor) students, while the overall exam score decreased with 0.779 points, about $0.47 \mathrm{SD}$, for poor (compared to 0.433 for non-poor) students.

To better understand why the camera installation leads to diverging educational outcomes for poor and non-poor students, we also adjust for ability differences between students. Because we only have ability for a smaller sample of students, we first confirm in columns (2), (5) and (8) that this selection only has a marginal impact on the estimates of interest. When adding ability controls in columns (3), (6) and (9) the estimates of the camera interacted with the poor indicator are only slightly lower than the estimates from the specification without ability controls. This is reassuring as it suggests that mean-reversion is not driving the differences in results across groups. It also means that even for students of the same ability, we do observe a diverging pattern for educational outcomes. This, in turn, indicates that the anti-corruption campaign (through the added impact of monitoring) induced more inequality of opportunity for poor students of similar ability.

In Table 5 we compare the written (high stakes) and the oral (low stakes) Romanian exams. Interestingly, we do not see any statistically significant estimates for the camera effects interacted with poor for the oral exam, hence supporting the conclusion that the differential effects of the camera policy for poor and non-poor students is real.

In Tables 4 and 5 we have omitted the results for the year effects interacted with poor. From these results shown in the online Appendix B, Tables B2 and B3, particularly for the exam scores, we see little evidence of a differential impact between poor and non-poor students over time (not captured by the camera effect), especially once we control for ability. ${ }^{42}$ This conclusion is also supported by the estimates using the oral exam.

Figure B2 (online Appendix B) provides an alternative way of presenting the heterogeneous effects, by displaying the written Romanian exam score distributions separately by poverty status for 2010 (unhindered corruption) compared with 2012 (little or no corruption). The score distributions display a large frequency shift from high to low scores in 2012 relative to 2010 for both poor and non-poor, but more pronounced for the already disadvantaged poor students. As we saw in the estimations above this is likely driven by the monitoring effect.

\footnotetext{
${ }^{42}$ The specifications in these tables exclude county fixed effects interacted with yearly trends, in order to obtain easy to interpret coefficients for the year indicators and the poor by year interactions.
} 
To conclude, the heterogeneity results shown in this section indicate an interesting finding: poor students may perform worse in a less corrupt system, owing to the introduction of monitoring in a system of increased threats of punishment. This is actually not in line with our prior that the non-poor would lose the most from reduced corruption. Intuitively, the nonpoor should be able to afford the hefty individual bribes, as well as gifts and private tutoring with in-class teachers. Moreover, those from a privileged economic background typically also enjoy a high social standing, which should grant them easy access to the nepotistic networks. However, in the pre-campaign years, both poor and non-poor students benefited from collective corruption (mass in-class cheating), which is the only form the cameras could deter. Overall, if the campaign would eliminate both collective and individual forms of corruption, everything else equal, we would expect the non-poor students to lose more in a non-corrupted environment. $^{43}$

\section{B. Mechanisms}

So what could explain the wider score gap between poor and non-poor students? One potential concern is that the proxy for poverty may reflect not only socioeconomic status but also some potential effect of the MHS program (used to define poverty status) on the recipients. In order to ensure that this is not the case, we compare students just below with students just above the cutoff income for receiving MHS in 2005-2006, which was the only year when funds were short of the demand and some eligible students did not receive the money (see online Appendix B, Table B10 and Figure B3). The RD estimate of the treatment effect is insignificant, indicating that the MHS program treatment is not a concern here. We therefore proceed to discuss some other potential channels leading to the observed increased score gap:

i) Increased parental investment or student effort for the non-poor. It is possible that some, particularly the non-poor students and their parents may have substituted bribes for more time spent working on exam preparation or on private tutoring. To rule out higher investment through private tutoring we look into additional data from the Romanian Household Budget Survey and observe no increase in private tutoring for high school students post- relative to pre-campaign years. Also, evidence from the low-stake oral exam (for the full

\footnotetext{
${ }^{43}$ We also estimate the campaign effects separately by our proxy for ability and by gender (see the online Appendix B, Tables B6 and B7). The results consistently show that the groups that were underperforming before the campaign (low-ability students, as defined by an ability measure below the median and male students) have even lower scores when monitoring and punishment are introduced. Thus, our estimates show that disadvantaged students became even worse off following the corruption-fighting initiatives. In the case of ability, while our proxy is not ideal (as it could also be inflated through corruption or favouritism) the campaign revealed a picture that is closer to the true standing of students.
} 
sample and separately for the poor and non-poor) seems to suggest that these channels are not driving our different results for poor and non-poor students. ${ }^{44}$

ii) Stronger cheating norms for the poor. One attempt to dismiss this channel is to look at how likely the poor and non-poor students are to be eliminated from the exam for cheating attempts. All students are randomly allocated in classes and the proctors do not know their identities (i.e. who is poor and non-poor). Hence, unless the poor have differential cheating norms from the non-poor, we should see no difference before 2011 by poverty status among those eliminated from the exam on the attempt of cheating. Indeed, our results tend to indicate no difference between poor and non-poor students in the probability of being eliminated (see the online Appendix B, Table B8). ${ }^{45}$

iii) Tougher grading. Because of the anti-corruption campaign, some evaluators may now be tougher on grading e.g., in order to avoid suspicions of corruption. However, it is unlikely that poor students would get penalized more for at least two reasons. First, we find that it is mainly the monitoring part of the campaign that drives the increased differences in exam scores between poor and non-poor students, while the cameras could only impact the behavior in class, not the grading. Second, we show (in Table 4) that the estimated differences in the effects for poor vs. non-poor only decrease marginally if we condition on ability. It is unlikely that students of similar ability should be graded tougher because of their poverty status, especially since the tests are anonymized and names revealed after marking. Still, we cannot fully exclude that tougher grading may partly account for the overall post-campaign score drop.

iv) Collective vs. individual bribes. We believe that one key to understanding the detrimental effects of the campaign on the poor lies in the various mechanics of the bribing process. If poor cheat as much as rich, without being able to afford bribes, the poor students' ability to take part in the fraud can only come as a result of free-riding. A good candidate explanation for this opportunity lies in the mechanism of collective bribing, which is essentially used to provide a "public good." If some students contribute, the benefit is collective and everyone, including poor students, can take advantage of the slack proctoring. Given some level of ability, the annihilation of cheating practices (likely coupled with particular unobserved traits, like motivation and the educational investment of poor students

\footnotetext{
${ }^{44}$ At least in 2011, the monitoring policy was announced just before the exam leaving little time for additional preparation. Since our results remain robust if we exclude year 2012, we conclude changes in effort are unlikely to confound the short term effect of the camera.

${ }^{45}$ In addition, in the online Appendix B Table B9 we show that the probability to pass the Romanian exam right at the cutoff (scores between 5 and 6), as opposed to failing, decreases due to the cameras (cheating in class is reduced, but not only at the threshold, as seen in the negative significant effects of the camera at all except the top scores), but not differentially across poor and non-poor students.
} 
throughout high school) generates lower results for the poor students. This implies that monitoring and punishment reveal wide pre-existing inequalities, previously concealed by corruption. A complementary explanation may lie in that only richer students can afford individual bribes. Recognizing the existence of a well-developed market for bribes, the poor student could not afford the required amounts or services. Moreover, following the implementation of the anti-corruption campaign it is likely that teachers could have substituted collective for more individual bribes, pricing out the poor students. ${ }^{46}$ While we cannot totally exclude the individual bribes (i.e., non-poor students under CCTV surveillance might have looked for a different way to boost their scores) it seems that the collective bribes are the main channel.

\section{The Short-Term Impact of the Anti-Corruption Campaign: Evidence from}

\section{Admission into an Elite University}

As revealed in the heterogeneity analysis, the corruption-fighting campaign led to a reshuffling of the students in the score distribution, by income. This may have direct implications for the selection of students into higher education. ${ }^{47}$ In this section we document the short-term consequences of the anti-corruption campaign by using admission data from an elite university in Romania. ${ }^{48}$ This university admits about the same number of students every year; all admitted students are ranked according to an overall score and the top 55 to $65 \%$ are exempt from the tuition fee (la buget), while the rest pay a monthly fee. ${ }^{49}$ We managed to get data for the admitted students at this elite university from 2009 to 2012 which we can merge with our main data and obtain a sample of 15,821 admitted students with a full education history. ${ }^{50}$ In what follows we label the group of tuition-exempt students "top students" and the group of tuition-paying students "good students."

\footnotetext{
${ }^{46}$ This type of displacement effect has been documented in the CCTV and crime literature. See Priks (2015).

${ }^{47}$ The total number of students in higher education (university) decreased from 775,319 in 2009 to 464,592 in 2012. The biggest drop took place at the private universities (from more than 300,000 to less than 100,000 students in four years), while the number of students enrolled (regardless of year of study) at public universities decreased from about 452,892 in 2009 to 364,916 in 2012.

${ }^{48}$ This is one of the oldest and highly regarded universities in Romania, with a long tradition of attracting elite students from all over the country. Students admitted here are usually in the top $15 \%$ of the overall high school scores and Baccalaureate grades. The proportion of accepted students coming from CCTV-monitored counties is about $77 \%$.

${ }^{49}$ The number of students admitted to the university was relatively constant across years: 4,507 (in 2009), 3,813 (in 2010), 3,977 (in 2011), and 3,524 (in 2012); students are exempt from the tuition fee (la buget) contingent on the Ministry of Education's budgetary allocation each year; the remaining students need to pay a tuition fee of roughly $85 \mathrm{USD} / \mathrm{month}$.

${ }^{50}$ We cannot fully merge the two data sets because we are missing some data on the variables needed for the merge: the Baccalaureate score for some students (who are from older cohorts), the poverty and/or ability measure for about 2,400 students. The attrition rate is however fairly constant across years, at less than $10 \%$. Note that our final sample of 15,821 students includes 698 students who took the Baccalaureate at least one year before the university admission (i.e., about $85 \%$ took the Baccalaureate in 2009 and 2010 and applied in 2011 and 2012, respectively). This may signal that our results are contaminated with students who got accepted with inflated Baccalaureate grades. In the regressions below we also control for these students.
} 
To understand whether there is any change in the composition of students admitted in the elite higher education due to corruption-reducing measures, in Table 6 (columns 1-2 - all students; column 3-4 - top students; column 5-6 -good students), we provide estimates from regressions based on equation (1), but where the dependent variable is the poverty indicator. We only show the camera indicator because we cannot infer anything from the changes in the composition in terms of poverty across years because the admission rules changed slightly every year. ${ }^{51}$ Hence, we can only credibly separate out the effect of camera monitoring on the poverty composition of admitted students.

The camera estimate in columns (1) and (2) show that admitted CCTV-monitored students are $2.4 \%$ less likely to be poor than those not monitored. Interestingly, the results in columns (3)-(4) for the top students show that the CCTV-monitored are less likely to be poor. The results in columns (5)-(6) for good students mirror the results for top students, but are insignificant.

As an additional exercise, we run the same regressions on a subsample of Baccalaureate students who were in the top $20 \%$ of the final Baccalaureate scores each year. We expect these students to be the top contenders for elite universities. The estimates, displayed in columns (7) and (8), convey the same effects of the campaign on student composition that we see for the university admission sample. We note that estimates are very similar when we include ability as a control suggesting that the reason for this change in the composition at the top is not because of ability differences. ${ }^{52}$

Taken together, these estimates strengthen the finding that the anti-corruption campaign resulted in increased inequality between poor and non-poor students. The poor students had significantly reduced chances of entering higher education, especially those with tuitionexempt status.

\section{Conclusions and Discussion}

This paper adds a new building block to the understanding of corruption in two dimensions. Firstly, it provides evidence that monitoring increases the effectiveness of the

\footnotetext{
${ }^{51}$ While the Baccalaureate grade remains the most important piece of the final admission score, its share changed from $50 \%$ of the admission score (in addition to 25\% high school grades and 25\% the university's own admission exam) in 2009 and 2010 to $67 \%$ (and 33\% high school grades) in 2011 and $100 \%$ of the admission score in 2012. This change implies that the 2011 and particularly the 2012 admission scores were far less inflated than earlier, due to both the anti-corruption policy and the change in admission rules, reflecting the true composition of students.

${ }^{52}$ In addition, we estimate the composition of university admitted and top Baccalaureate students in terms of ability. The results, which we do not report here, suggest that monitoring contributed to an improvement in ability, suggesting an increase in the efficiency and meritocracy of allocating talent into higher education. However, the results confirm that the poor students' chances to reach the top places were significantly reduced.
} 
punishment threats in reducing corruption even in settings where the potential gains from corruption are very large. Second, it analyzes the ramifications of fighting corruption from a distributional perspective - an issue largely overlooked in previous studies.

We make use of a setting where corruption in education is rampant and has large gains for students, i.e., the Romanian national school-leaving exam, the Baccalaureate. We exploit a nationwide anti-corruption campaign that began in 2011 featuring both increased credible threats of punishment (for teachers and students) and increased monitoring during the exam. We make use of the variation across years and counties in closed-circuit TV (CCTV) exam monitoring to calculate the effect of the campaign on Baccalaureate exam scores. Our results indicate that the campaign was more effective when the additional monitoring part of the campaign was in place. While the punishment component was implemented in the whole country at the same time, because of its strict implementation and the use of a placebo exercise, we can say that increased punishment brought about by the campaign has curbed corruption, as seen in the overall drop in test scores. We conclude that monitoring enhances the effectiveness of punishment.

After having established that the campaign had a drastic effect on the test scores and on the average student's probability of passing the Baccalaureate high-stake exam, we show the distributional effects of curbing corruption by looking at the heterogeneous impact by students' poverty status. We find that the poor students perform even worse in a non-(less) corrupt system, an ex-ante unexpected pattern.

Finally, we also look at the composition of students at an elite university. The results strengthen the finding that the anti-corruption campaign revealed a greater inequality between poor and non-poor students than the apparent pre-campaign level. More exactly, we find that poor students' chances of entering higher education went down significantly, especially with regard to tuition-exempt admission.

An important lesson from these results is that anti-corruption programs are not a cure for all ills. In terms of inequality of opportunity, the finding that poor students do worse in a non-corrupt state is especially important for policy makers. This result uncovers the wide preexisting inequalities between the poor and the well-off students, which corruption had only concealed. The implication is that, in addition to maintaining the anticorruption strategies, there is a need for more in-depth investigation of the differences in achievement between poor and non-poor. The implications of these findings extend to other countries, such as Moldova or Cambodia, where, similar anti-corruption measures for high-stake exams have been discussed and implemented, and where the initial inequality level was already very high. 


\section{REFERENCES}

Baicker, K. and Staiger, D. (2005) "Fiscal Shenanigans, Targeted Federal Health Care Funds, and Patient Mortality", Quarterly Journal of Economics 120 (1): 345-386.

Banerjee, A., Duflo, E. and Glennerster, R. (2008) "Putting a Band-Aid on a Corpse. Incentives for Nurses in the Indian Public Health Care System", Journal of the European Economics Association, 6(2-3), pp. 487-500.

Banerjee, A., Mullainathan, S. and Hanna, R. (2012) "Corruption”, NBER Working Paper No. 17968, April.

Becker, G. S. and George J. Stigler (1974) "Law Enforcement, Malfeasance, and Compensation of Enforcers," The Journal of Legal Studies, University of Chicago Press, vol. 3(1), pp. 1-18.

Becker, G. S. and Tomes, N. (1986) "Human Capital and the Rise and Fall of Families", Journal of Labor Economics, University of Chicago Press, 4(3), pp. 1-47, July.

Black, S. E. \& Devereux, P. J. (2011) "Recent Developments in Intergenerational Mobility", Handbook of Labor Economics, Elsevier.

Bertoni, M., Brunello, G, Rocco, L. (2013) "When the cat is near, the mice won't play: The effect of external examiners in Italian schools", Journal of Public Economics 104, pp. 65-77.

Borcan, O., Lindahl, M. and Mitrut, A. (2014) "The Impact of an Unexpected Wage Cut on Corruption: Evidence from a "Xeroxed" Exam", Journal of Public Economics, Volume 120, December, pp. 32-47.

Chapell, M.S., Blanding, Z.B., Silverstein, M.E., Takahashi, M., Newman, B., Gubi, A. (2005) "Test anxiety and academic performance in undergraduate and graduate students", Journal of Educational Psychology, 97, pp.268-274.

Choe, C., Dzhumashev, R., Islam, A. and Khan, Z. H. (2013) "The Effect of Informal Networks on Corruption in Education: Evidence from the Household Survey Data in Bangladesh", Journal of Development Studies, 49(2), pp. 238-250.

Di Tella, R. \& Schargrodsky, E. (2003) "The Role of Wages and Auditing during a Crackdown on Corruption in the City of Buenos Aires," Journal of Law and Economics, University of Chicago Press, vol. 46(1), pp. 269-92.

Duflo, E., Hanna, R. and Ryan, S. (2012) "Incentives Work: Getting Teachers to Come to School”, American Economic Review, 102(4), pp. 1241-78.

Emran, M.S. Islam, A. and Shilpi, F. (2013) "Admission is Free Only if Your Dad is Rich! Distributional Effects of Corruption in Schools in Developing Countries", Monash Economics Working Papers 11-13, Monash University, Department of Economics.

Ferraz, C. and Finan, F. (2008) "Exposing Corrupt Politicians: The Effects of Brazil's Publicly Released Audits on Electoral Outcomes", The Quarterly Journal of Economics, MIT Press, 123(2), pp. 703-745.

Ferraz, C. and Finan, F. (2011) "Electoral Accountability and Corruption: Evidence from the Audits of Local Governments", American Economic Review, American Economic Association, 101(4), pp. 1274-1311, June.

Ferraz, C., Finan, F. and Moreira, D. B. (2012) "Corrupting learning", Journal of Public Economics, 96(9-10), pp. 712-726.

Glewwe, P., Ilias, N. and Kremer, M. (2010). "Teacher Incentives”, American Economic Journal: Applied Economics, American Economic Association, 2(3), pp 205-27, July.

Hunt, J. (2007). "How corruption hits people when they are down", Journal of Development Economics, 84(2), pp. 574-589. 
King, J., Mulligan, D. K. and Raphael, S. (2008) "The San Fransciso Community Safety Camera Program: An Evaluation of the Effectiveness of San Francisco's Community Safety Cameras", CITRIS Report, University of California, Berkeley

Lance Lochner \& Alexander Monge-Naranjo, 2012. "Credit Constraints in Education," Annual Review of Economics, Annual Reviews, vol. 4(1), pages 225-256, 07.

Mauro, P. (1995) “Corruption and growth”, Quarterly Journal of Economics, 110(3), pp. 681712.

Nagin, D.S., Rebitzer, J. B., Sanders, S. and Taylor, L. J. (2002). "Monitoring, Motivation, and Management: The Determinants of Opportunistic Behavior in a Field Experiment", American Economic Review, vol. 92(4), pp. 850-873.

Olken, B. (2006) "Corruption and the Costs of Redistribution: Micro Evidence from Indonesia" Journal of Public Economics, 90(4-5), May, pp. 853-870.

Olken, B. (2007) "Monitoring Corruption: Evidence from a Field Experiment in Indonesia", Journal of Political Economy, 115(2), April, pp. 200-249.

Olken, B. and Pande, R. (2012) "Corruption in Developing Countries", Annual Review of Economics, 4, pp. 479-505.

Pop-Eleches, C. (2009) "Abortion and child cognitive outcomes", mimeo, Columbia University.

Pop-Eleches, C., Urquiola, M. (2013) "Going to a Better School: Effects and Behavioral Responses", American Economic Review, 103(4), pp. 1289-1324.

Priks, M (2014). "Do Surveillance Cameras Affect Unruly Behavior? A Close Look at Grandstands", The Scandinavian Journal of Economics, 116(4), pp. 1160-1179.

Priks, M. (2015). "The Effects of Surveillance Cameras on Crime: Evidence from the Stockholm Subway", Economic Journal, forthcoming.

Reinikka, R. and Svensson, S. (2004). "Local Capture: Evidence From a Central Government Transfer Program in Uganda" The Quarterly Journal of Economics, MIT Press, 119(2), pp. 678-704.

Reinikka, R. and Svensson, J. (2005) "Fighting Corruption to Improve Schooling: Evidence from a Newspaper Campaign in Uganda", Journal of the European Economic Association, MIT Press, 3(2-3), pp. 259-267.

Rothstein, B. and Uslaner, E. (2005) "All for All: Equality, Corruption, and Social Trust Source," World Politics, 58(1), pp. 41-72.

Solon, G. (1999) "Intergenerational Mobility in the Labor Market", in Orley C. Ashenfelter and David Card (editors), Handbook of Labor Economics, 3A, Amsterdam.

Svensson, J. (2005) "Eight Questions about Corruption", Journal of Economic Perspectives, 19(3), pp.19-42

Welsh, B. C. and Farrington, D. P. (2003). "Effects of Closed-Circuit television on Crime", The ANNALS of the American Academy of Political Science, 587, pp. 110-135.

Welsh, B. C. and Farrington, D. P. (2009), "Public Areas CCTV and Crime Prevention: An Updated Systematic Review and Meta-Analysis", Justice Quarterly, 26, pp. 716-745.

You, J., Khagram, S. (2005) "A Comparative Study of Inequality and Corruption." American Sociological Review 70(1), pp.136-157. 


\section{FIGURES}

Figure 1. Baccalaureate score evolution 2004-2012, by early and late camera installation

\section{A: Average Romanian written exam scores}

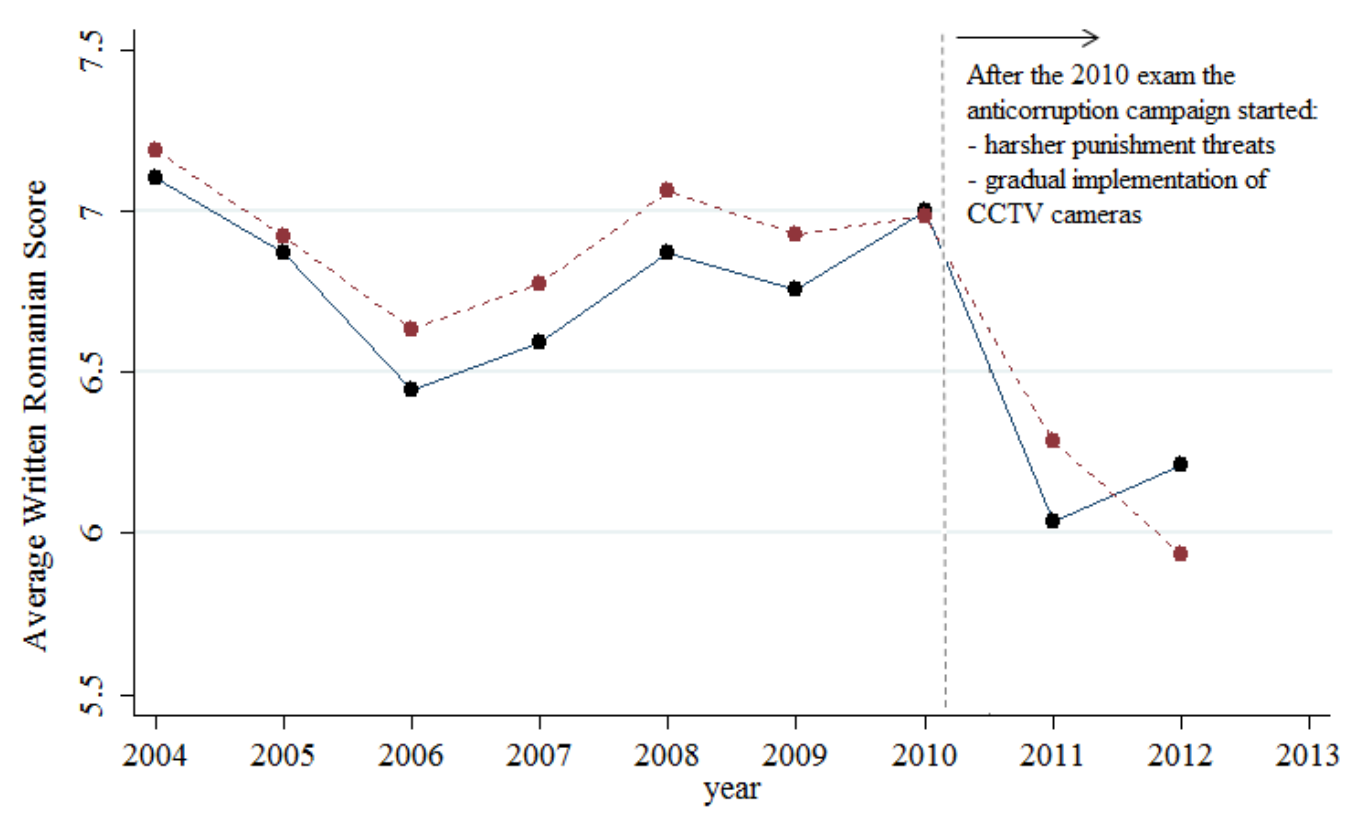

- Counties that installed cameras in 2011

Counties that installed cameras in 2012

\section{B: Average Pass Rates}

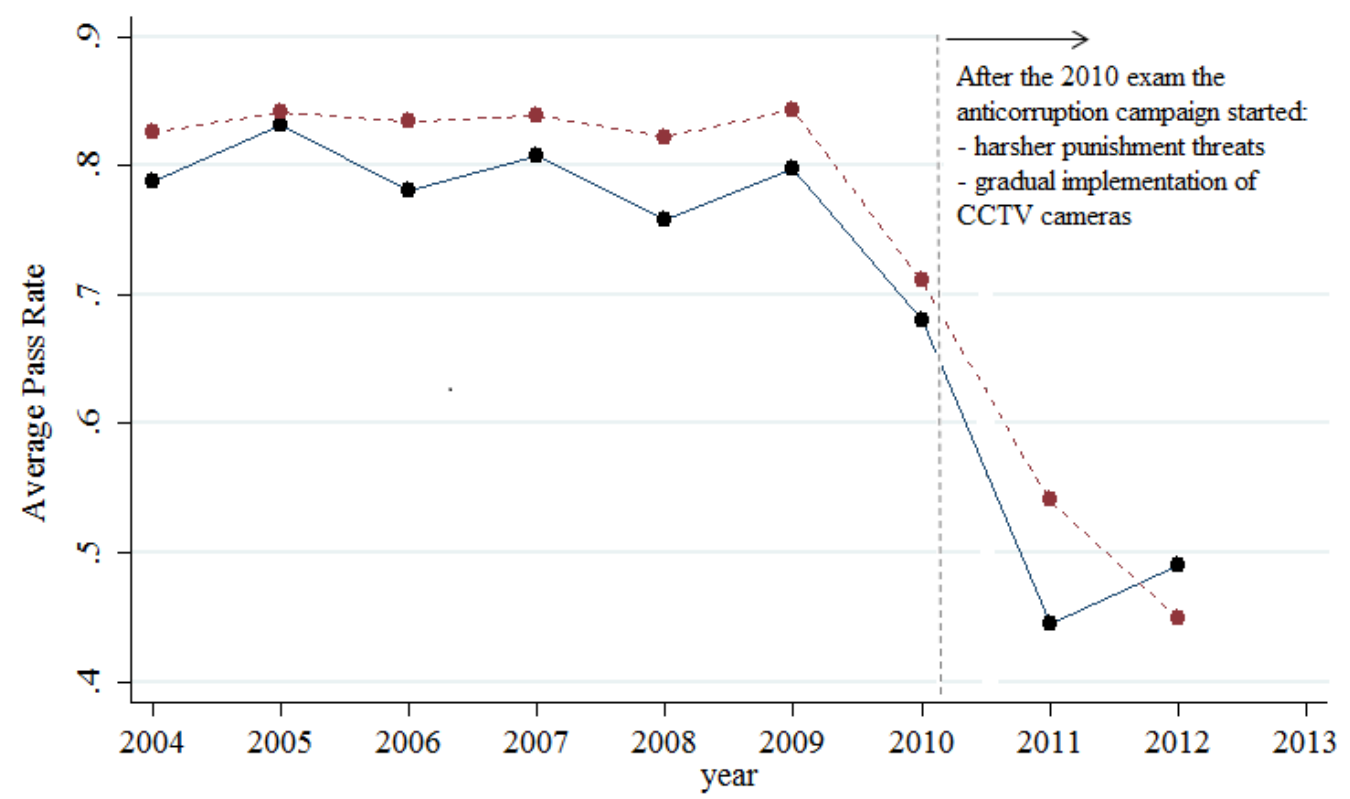

- Counties that installed cameras in 2011

Counties that installed cameras in 2012 


\section{C: Average overall Baccalaureate scores}

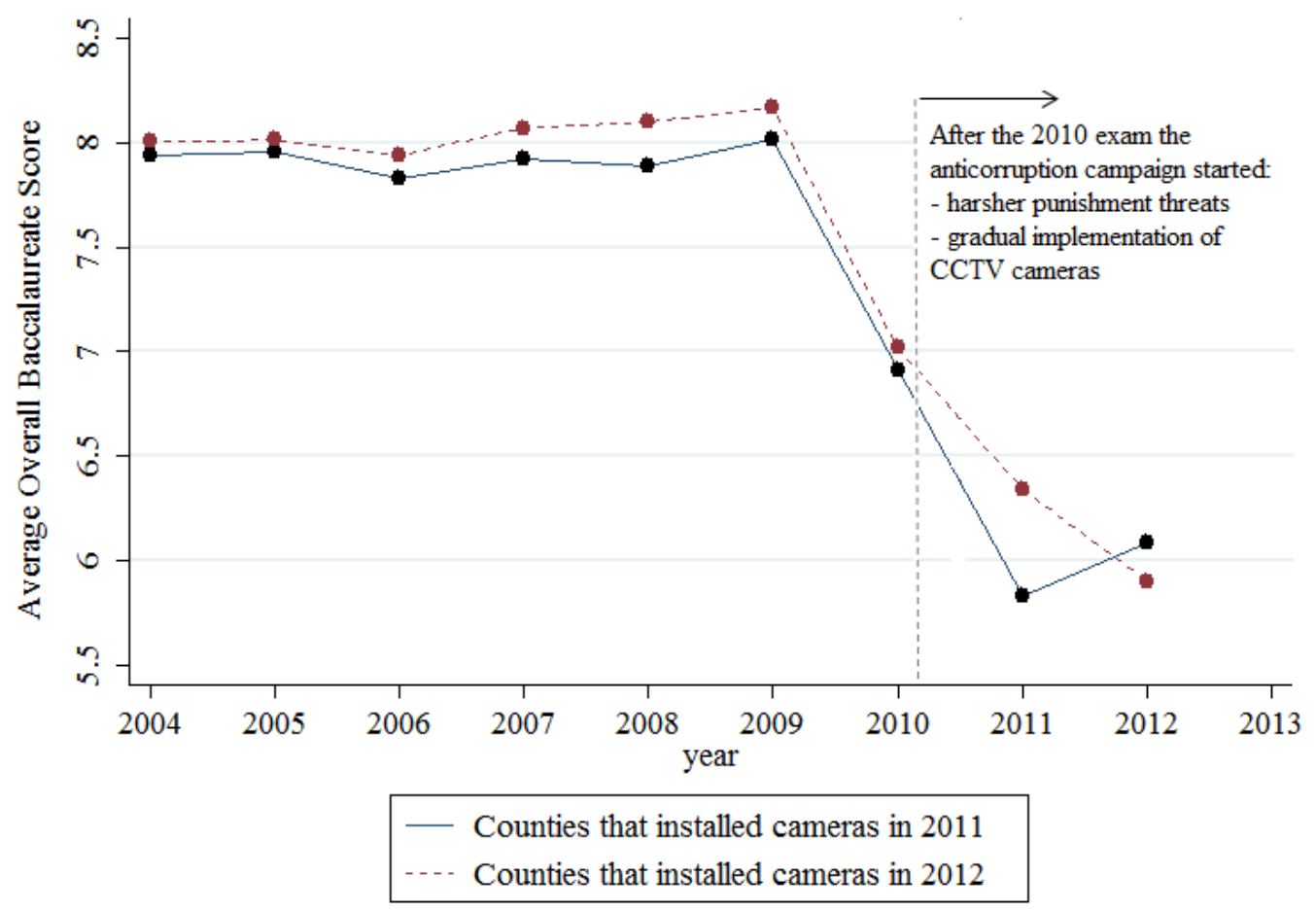

Notes: 1) The figure displays the average Romanian written exam scores (Figure 1A), overall pass rates (Figure 1B) and overall Baccalaureate exam scores (Figure 1C), separately for counties that implemented the cameras in 2011 and those that implemented the cameras in 2012. The average scores are displayed on the y-axis, while the $\mathrm{x}$-axis displays the years from 2004 to 2012.

2) The drop in overall scores and pass rates in 2010 is due to a change in exam structure which made the exams harder to pass which is explained more in the paper. 
Figure 2. Baccalaureate average scores, by poverty and by early and late installation 2006-2012
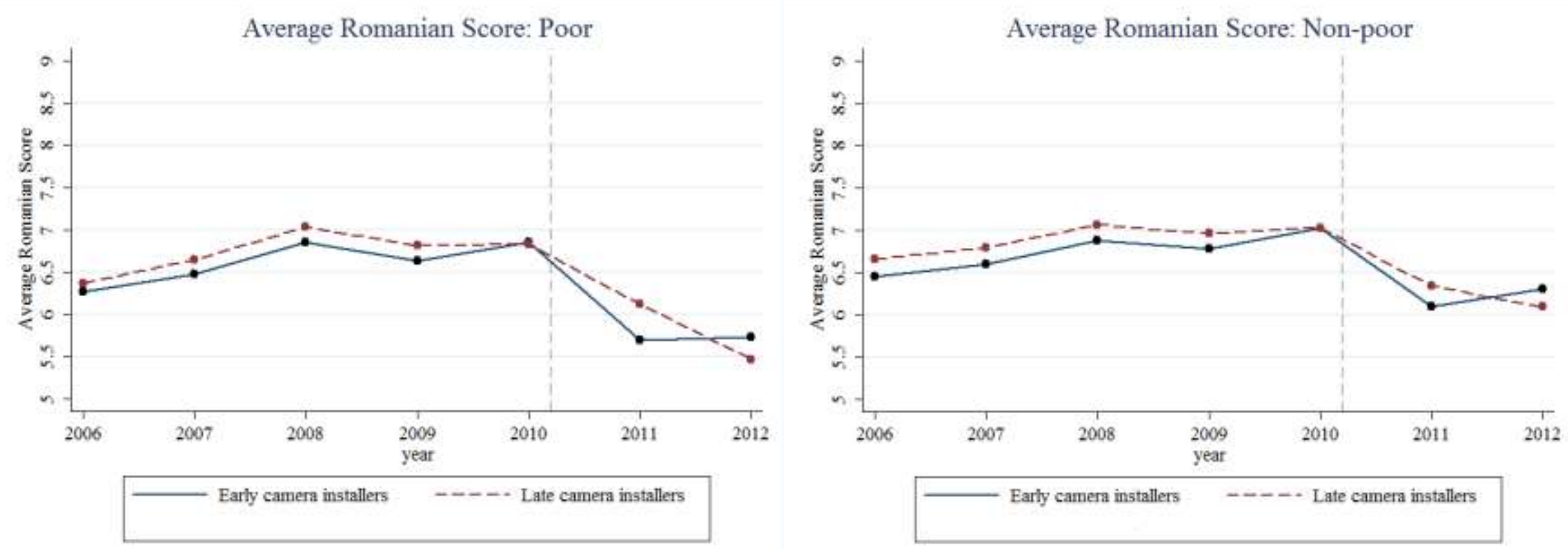

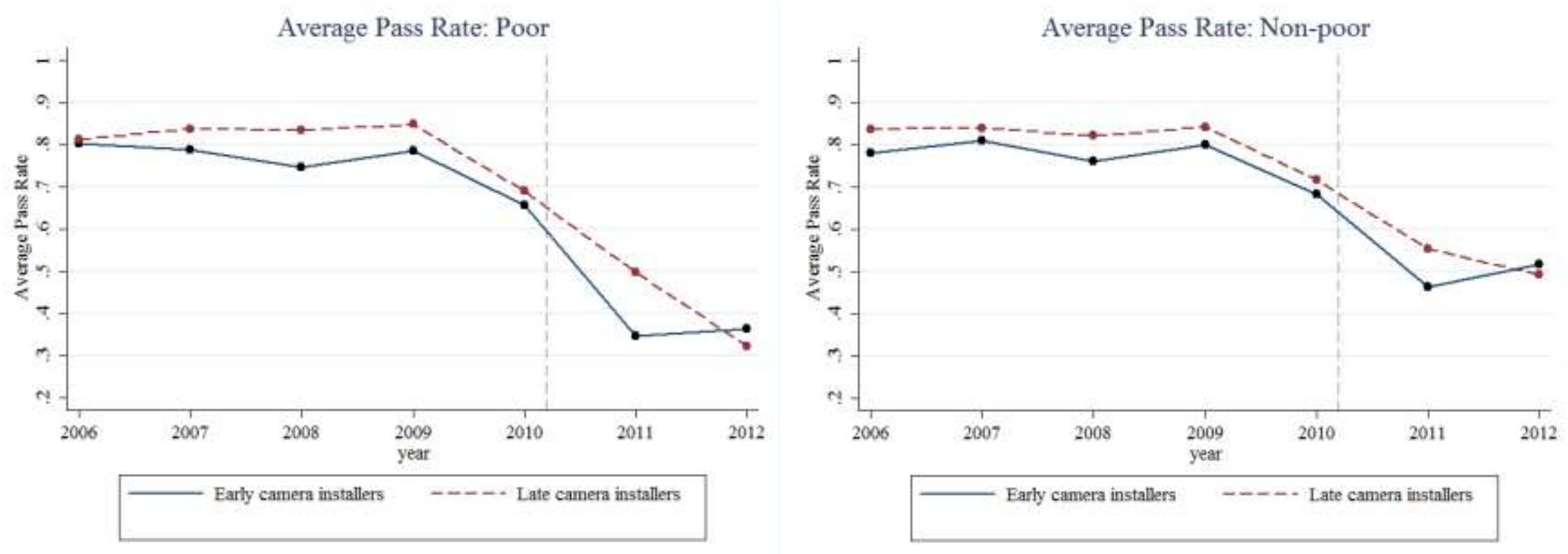

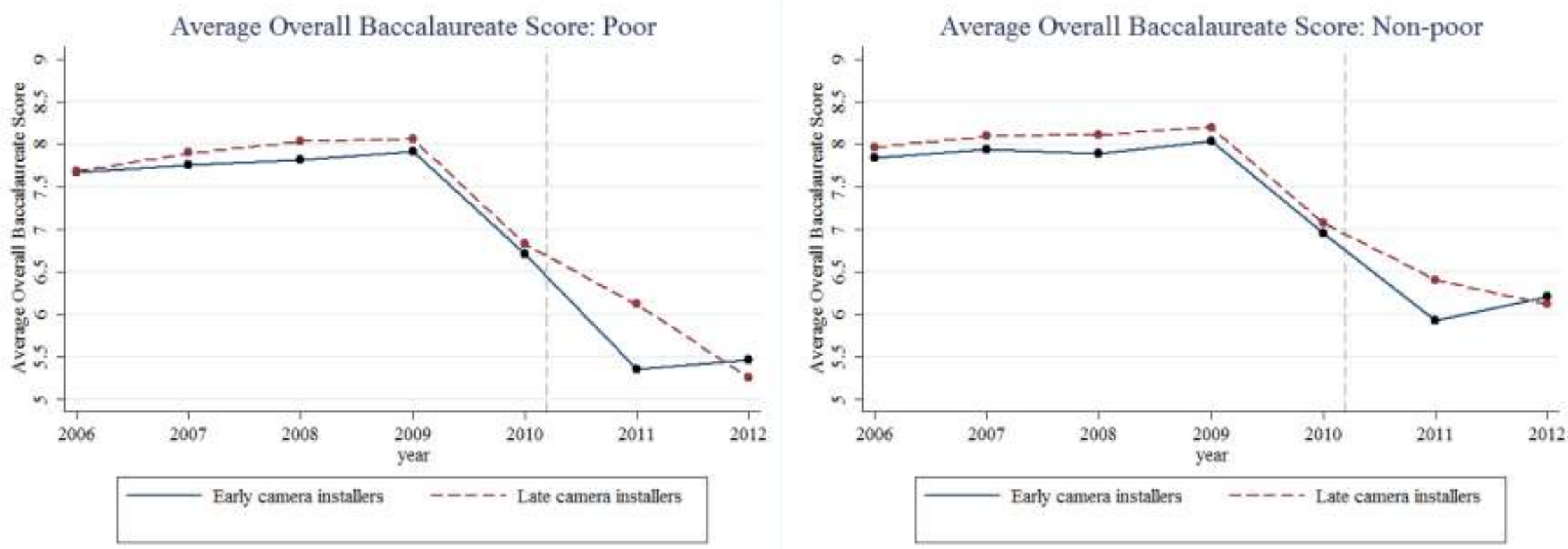

Notes: 1) The figures display the average Romanian written exam scores (top), Baccalaureate pass rates (middle) and the overall Baccalaureate score (bottom) for the 2006-2012 school years, by poverty status and separately for counties that did and did not implement the camera in 2011.

2) The average scores are displayed on the $y$-axis, while the $x$-axis displays the years. 
Figure 3. Baccalaureate National Pass Rates in Romania and Moldova, 2007-2014
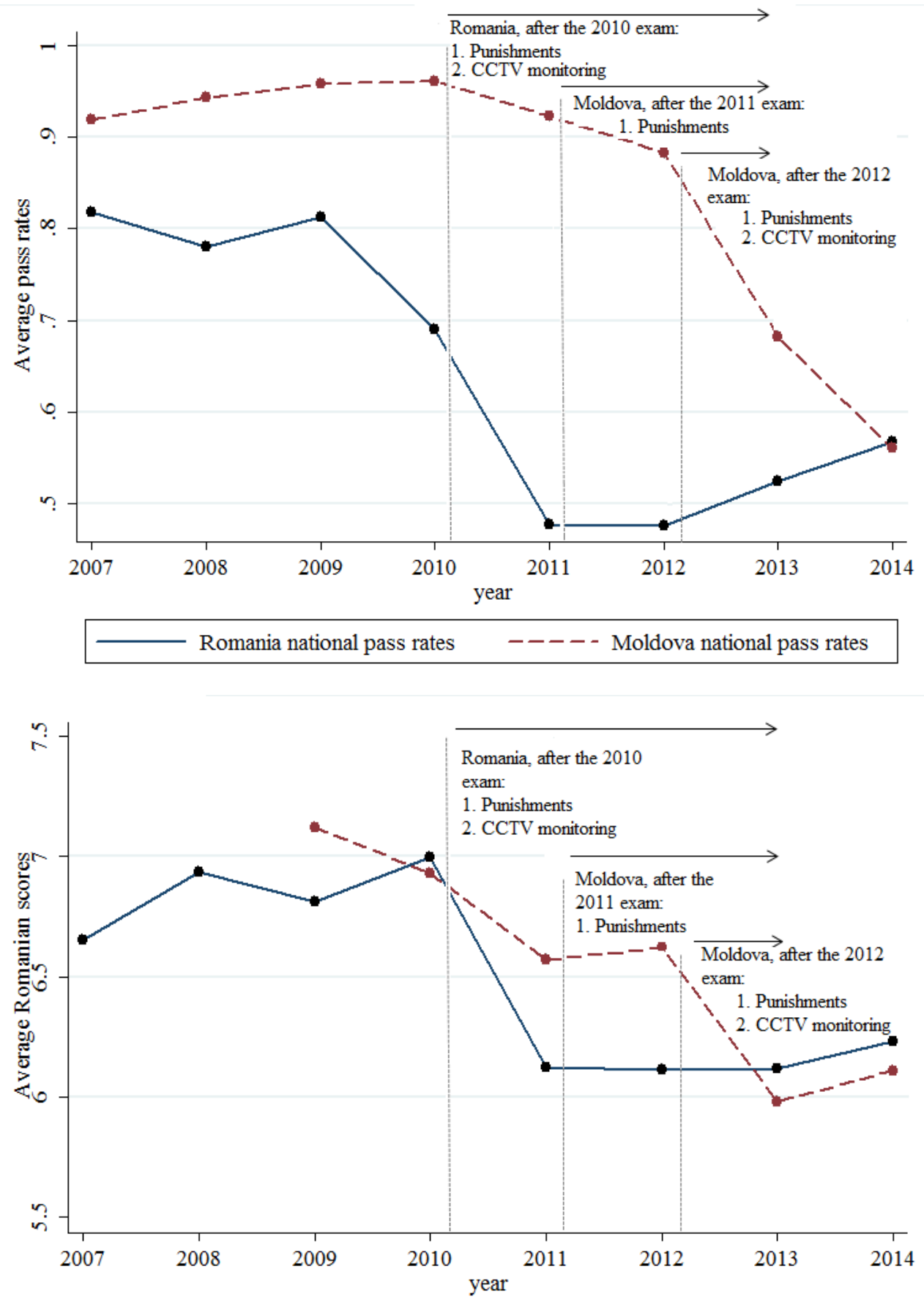

Romania average Romanian score - - - Moldova average Romanian score

Notes: 1) The figure displays Romanian exam average scores and the average national pass rates in 2007-2014 in Romania and Moldova.

2) The figures for Moldova are retrieved from the government website www.bloguvern.md and the Agency for Quality Assessment. The figures for Romania are the authors' own calculations using the available individual-level datasets, except for the years 2013 and 2014 when aggregate numbers are retrieved from the Ministry of Education.

3) The average pass rates and Romanian scores are displayed on the y-axis, while the $x$-axis displays the years from 2007 to 2013. The vertical lines at 2011, 2012 and 2013 indicate when the anticorruption policies first took effect, influencing the Baccalaureate exam. 


\section{TABLES}

Table 1. Summary statistics for the working sample

\begin{tabular}{|c|c|c|c|c|c|c|c|c|}
\hline & \multicolumn{2}{|c|}{2009} & \multicolumn{2}{|c|}{2010} & \multicolumn{2}{|c|}{2011} & \multicolumn{2}{|c|}{2012} \\
\hline & Mean & S.D. & Mean & S.D. & Mean & S.D. & Mean & S.D. \\
\hline Written Romanian score & 6.813 & 1.819 & 7.017 & 1.664 & 6.147 & 2.102 & 6.143 & 2.138 \\
\hline Baccalaureate Pass & 0.813 & 0.390 & 0.692 & 0.462 & 0.482 & 0.500 & 0.482 & 0.500 \\
\hline Overall Baccalaureate score & 8.057 & 1.150 & 6.969 & 1.647 & 6.033 & 1.998 & 6.049 & 2.142 \\
\hline Oral Romanian score & & & 2.459 & 0.697 & 2.503 & 0.691 & 2.502 & 0.702 \\
\hline Percentile rank oral ${ }^{1)}$ & & & 0.487 & 0.252 & 0.506 & 0.249 & 0.510 & 0.249 \\
\hline Percentile rank written ${ }^{1)}$ & & & 0.578 & 0.256 & 0.454 & 0.296 & 0.456 & 0.298 \\
\hline Poor & 0.166 & 0.372 & 0.175 & 0.380 & 0.185 & 0.388 & 0.201 & 0.401 \\
\hline Male & 0.483 & 0.500 & 0.490 & 0.500 & 0.480 & 0.500 & 0.463 & 0.499 \\
\hline Theoretical track & 0.447 & 0.497 & 0.434 & 0.496 & 0.447 & 0.497 & 0.469 & 0.499 \\
\hline Rural & 0.057 & 0.232 & 0.065 & 0.246 & 0.067 & 0.250 & 0.059 & 0.236 \\
\hline Low ability ${ }^{2)}$ & 0.509 & 0.500 & 0.514 & 0.500 & 0.500 & 0.500 & 0.468 & 0.499 \\
\hline $\mathrm{N}^{3)}$ & 196,687 & & 195,755 & & 182,939 & & 156,124 & \\
\hline
\end{tabular}

Notes: The table displays descriptive statistics by year for our working sample of students who took the Baccalaureate exam in 2009-2012. The observations for all years sum up to the number of observations in columns 5-8 in Table 2. Our main outcome variables are: "written Romanian score", which is the student's score in the Romanian language written exam (scale 1-10); "Baccalaureate pass", which is an indicator equal to 1 for students that passed the overall Baccalaureate exam, and 0 for students who failed; "Overall Baccalaureate score", which is the student's average score in the overall Baccalaureate exam (scale 1-10).

1) In the regression analysis we use the standardized percentile rank scores at the written and oral Romanian exams with respect to 2010 overall sample mean and standard deviation;

2) The low ability variable is an indicator for students that have $5^{\text {th }}-8^{\text {th }}$ grade scores below the median score in the sample and is available only for $70 \%$ of the sample;

3) The number of observations for the Romanian written and oral exams is slightly smaller. This is because students being absent from an exam count as missing score and failing the overall exam. 
Table 2. The impact of the anti-corruption campaign: main results

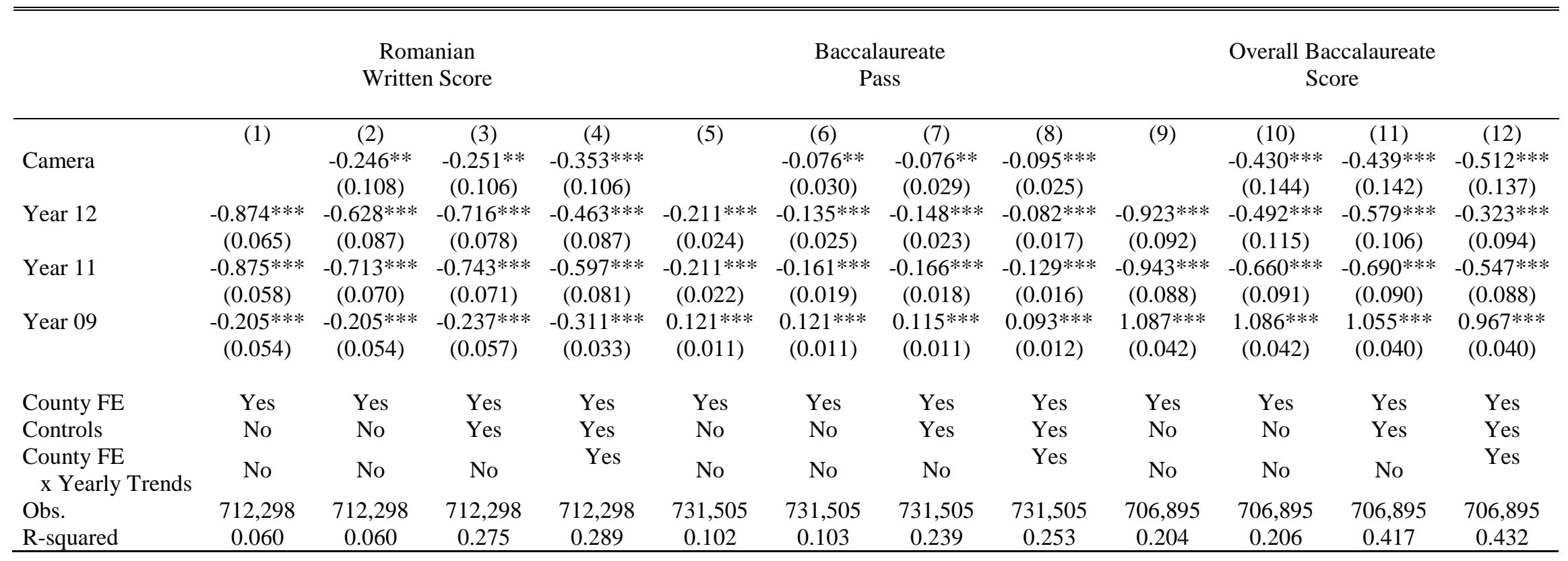

Notes: 1) The table displays the OLS estimates from the baseline DD specifications that regress the Romanian exam scores, exam pass probability and overall Baccalaureate scores on the "Camera" treatment and year dummies, for our working sample of students who took the Baccalaureate exam in 2009-2012. The "Camera" treatment is equal to 1 for all students in counties that implemented the CCTV monitoring in 2011 and in all counties in 2012, and 0 otherwise.

2) The controls include: poverty status, gender, theoretical track and rural indicators.

3) The standard errors are clustered at county level (there are 42 clusters).

*** Significant at the 1 percent level.

** Significant at the 5 percent level.

* Significant at the 10 percent level. 


\begin{tabular}{|c|c|c|c|c|c|c|c|c|}
\hline & \multicolumn{4}{|c|}{$\begin{array}{c}\text { High-stakes exam: } \\
\text { Written Romanian exam } \\
\text { (Percentile rank, standardized) }\end{array}$} & \multicolumn{4}{|c|}{$\begin{array}{c}\text { Low-stakes exam: } \\
\text { Oral Romanian exam } \\
\text { (Percentile rank, standardized) }\end{array}$} \\
\hline & (1) & $(2)$ & (3) & (4) & $(5)$ & (6) & $(7)$ & $(8)$ \\
\hline Camera & & $\begin{array}{c}-0.171 * * * \\
(0.048)\end{array}$ & $\begin{array}{c}-0.173 * * * \\
(0.049)\end{array}$ & $\begin{array}{c}-0.175 * * * \\
(0.049)\end{array}$ & & $\begin{array}{c}0.023 \\
(0.020)\end{array}$ & $\begin{array}{c}0.021 \\
(0.019)\end{array}$ & $\begin{array}{c}0.019 \\
(0.019)\end{array}$ \\
\hline Year 12 & $\begin{array}{c}-0.475 * * * \\
(0.032)\end{array}$ & $\begin{array}{c}-0.303 * * * \\
(0.037)\end{array}$ & $\begin{array}{c}-0.351 * * * \\
(0.038)\end{array}$ & $\begin{array}{c}-0.205 * * * \\
(0.047)\end{array}$ & $\begin{array}{c}0.090 * * * \\
(0.014)\end{array}$ & $\begin{array}{c}0.067 * * \\
(0.025)\end{array}$ & $\begin{array}{c}0.038 \\
(0.024)\end{array}$ & $\begin{array}{c}0.049 * * * \\
(0.018)\end{array}$ \\
\hline Year 11 & $\begin{array}{c}-0.484 * * * \\
(0.029)\end{array}$ & $\begin{array}{c}-0.371 * * * \\
(0.036)\end{array}$ & $\begin{array}{c}-0.385 * * * \\
(0.039)\end{array}$ & $\begin{array}{c}-0.311 * * * \\
(0.043)\end{array}$ & $\begin{array}{c}0.075 * * * \\
(0.011)\end{array}$ & $\begin{array}{c}0.060 * * * \\
(0.018)\end{array}$ & $\begin{array}{c}0.053 * * * \\
(0.017)\end{array}$ & $\begin{array}{c}0.058 * * * \\
(0.015)\end{array}$ \\
\hline County FE & Yes & Yes & Yes & Yes & Yes & Yes & Yes & Yes \\
\hline Controls & No & No & Yes & Yes & No & No & Yes & Yes \\
\hline $\begin{array}{l}\text { County FE } \\
\text { x Yearly Trends }\end{array}$ & No & No & No & Yes & No & No & No & Yes \\
\hline Observations & 515,102 & 515,102 & 515,102 & 515,102 & 515,102 & 515,102 & 515,102 & 515,102 \\
\hline R-squared & 0.062 & 0.063 & 0.293 & 0.298 & 0.028 & 0.028 & 0.145 & 0.146 \\
\hline
\end{tabular}

Notes: 1) The table displays the OLS estimates from the baseline DD specifications that regress the Romanian written exam performance (columns 1-4) and the Romanian oral exam performance (columns 5-8) on the "Camera" treatment and year dummies, using the 2010-2012 data of our working sample. The regression specifications and "Camera" treatment are analogous to those reported in the notes of Table 2.

2) The Romanian oral exam performance does not count at all toward the Baccalaureate score, or university admission, and is simply indicated by a qualifier: "excellent", "good" or "sufficient". We assign scores 3, 2 and 1 to these qualifiers and then calculate the percentile rank scores associated. Thus, both dependent variables are expressed in standardized percentile rank scores with respect to the 2010 means and standard deviations.

3) The controls include: poverty status, gender, theoretical track and rural indicators.

4) The standard errors are clustered at county level (there are 42 clusters).

*** Significant at the 1 percent level.

** Significant at the 5 percent level.

* Significant at the 10 percent level. 
Table 4. Heterogeneous effects of the anti-corruption campaign by poverty: a fully interacted model

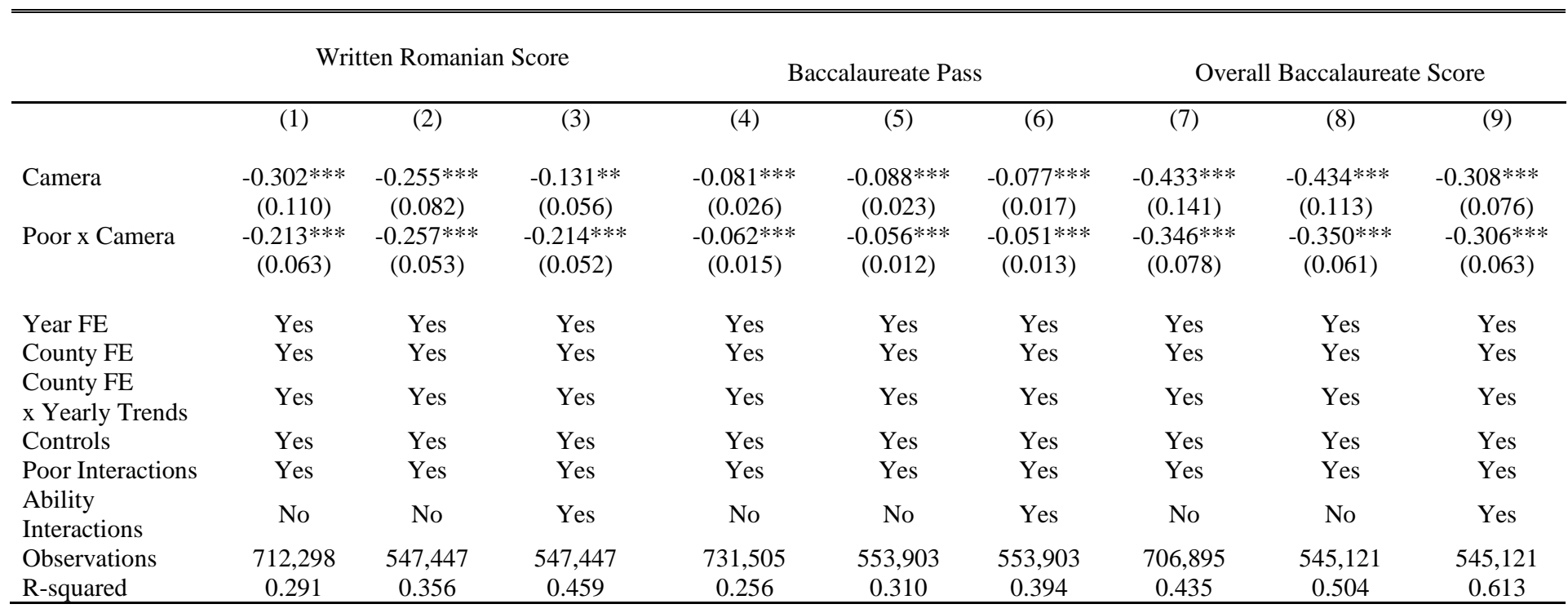

Notes: 1) The table displays the OLS estimates from the baseline DD specifications with interaction terms between poverty status and all variables for the 2009-2012 school years. The estimations include county fixed effects and county trends (and their interaction with poverty status). The dependent variables are: written Romanian exam scores (columns 1-3), Baccalaureate pass (columns 4-6) and overall Baccalaureate score (columns 7-9). The "Camera" treatment is defined as reported in the notes of Table 2.

2) Columns 1, 4 and 7 include only poverty status interactions with all variables, including county fixed effects and county trends, based on our working sample. Columns 2, 5 and 8 include only poverty status interactions, based on a subset of our working sample for which we have a proxy for ability. Columns 3, 6 and 9 include all interactions between an ability indicator and all variables, including county fixed effects and county trends. In columns 3, 6 and 9 we control for students of low ability, using an indicator equal to 1 for students with scores in $5^{\text {th }}-8^{\text {th }}$ grade below the median score in the sample.

3) Controls include: poor, gender, theoretical track and rural indicators.

4) The standard errors are clustered at county level (there are 42 clusters).

$* * *$ Significant at the 1 percent level.

** Significant at the 5 percent level.

* Significant at the 10 percent level. 
Table 5. Heterogeneous effects of the anti-corruption campaign by poverty, with controls for ability: a fully interacted model. Written vs. oral Romanian score, standardized with respect to 2010

\begin{tabular}{|c|c|c|c|c|c|c|}
\hline & \multicolumn{3}{|c|}{$\begin{array}{c}\text { High-stakes exam: } \\
\text { Written Romanian exam } \\
\text { (Percentile rank, standardized) }\end{array}$} & \multicolumn{3}{|c|}{$\begin{array}{c}\text { Low-stakes exam: } \\
\text { Oral Romanian exam } \\
\text { (Percentile rank, standardized) }\end{array}$} \\
\hline & (1) & (2) & (3) & (4) & (5) & (6) \\
\hline Camera & $\begin{array}{c}-0.151 * * * \\
(0.052)\end{array}$ & $\begin{array}{c}-0.140 \text { *** } \\
(0.043)\end{array}$ & $\begin{array}{c}-0.090 * * \\
(0.035)\end{array}$ & $\begin{array}{c}0.029 \\
(0.020)\end{array}$ & $\begin{array}{c}0.015 \\
(0.018)\end{array}$ & $\begin{array}{c}-0.003 \\
(0.014)\end{array}$ \\
\hline Poor x Camera & $\begin{array}{c}-0.105^{* * *} \\
(0.031)\end{array}$ & $\begin{array}{c}-0.115^{* * * *} \\
(0.026)\end{array}$ & $\begin{array}{c}-0.099 * * * \\
(0.026)\end{array}$ & $\begin{array}{l}-0.033 \\
(0.022)\end{array}$ & $\begin{array}{l}-0.019 \\
(0.021)\end{array}$ & $\begin{array}{l}-0.025 \\
(0.020)\end{array}$ \\
\hline Year FE & Yes & Yes & Yes & Yes & Yes & Yes \\
\hline County FE & Yes & Yes & Yes & Yes & Yes & Yes \\
\hline $\begin{array}{l}\text { County FE } \\
\quad \text { X Yearly Trends }\end{array}$ & Yes & Yes & Yes & Yes & Yes & Yes \\
\hline Controls & Yes & Yes & Yes & Yes & Yes & Yes \\
\hline Poor Interactions & Yes & Yes & Yes & Yes & Yes & Yes \\
\hline Ability Interactions & No & No & Yes & No & No & Yes \\
\hline Observations & 515,102 & 400,088 & 400,088 & 515,102 & 400,088 & 400,088 \\
\hline R-squared & 0.301 & 0.364 & 0.471 & 0.148 & 0.184 & 0.252 \\
\hline
\end{tabular}

Notes: 1) The table displays the OLS estimates from the baseline DD specifications with interaction terms between poverty status and all variables for the 2010-2012 school years. The estimations include county fixed effects and county trends (and their interaction with poverty status). The dependent variables are: the written Romanian exam scores (columns 1-3) and oral Romanian exam scores (columns 4-6). The "Camera" treatment is defined as reported in the notes of Table 2.

2) Columns 1 and 4 include only poverty status interactions all variables, including county fixed effects and county trends and is based on our working sample. Columns 2 and 5 include only poverty status interactions based on a subset of our working sample for which we have a proxy for ability. Columns 3 and 6 include all interactions between an ability dummy and all variables, including county fixed effects and county trends in Panel A. In columns 3 and 6 we control for students of low ability, using an indicator equal to 1 for students with scores in $5^{\text {th }}-8^{\text {th }}$ grade below the median score in the sample.

3) The Romanian oral exam performance does not count for the Baccalaureate score, or university admission, and is simply indicated by a qualifier: "excellent", "good" or "sufficient". We assign scores 3, 2 and 1 to these qualifiers and then calculate the percentile rank scores associated. Thus, both dependent variables are expressed in standardized percentile rank scores with respect to the 2010 means and standard deviations.

4) Controls include: poor, gender, theoretical track and rural indicators.

5) The standard errors are clustered at county level (there are 42 clusters).

*** Significant at the 1 percent level.

** Significant at the 5 percent level.

* Significant at the 10 percent level. 
Table 6. The composition in terms of poverty at the admission into an elite university and in the top $20 \%$ at the Baccalaureate

\begin{tabular}{|c|c|c|c|c|c|c|c|c|}
\hline & \multicolumn{2}{|c|}{$\begin{array}{c}\text { Poor admitted to an elite } \\
\text { university }\end{array}$} & \multicolumn{2}{|c|}{$\begin{array}{c}\text { Poor } \\
\text { in an elite } \\
\text { university } \\
\text { Tuition-exempt } \\
\text { (top students) }\end{array}$} & \multicolumn{2}{|c|}{$\begin{array}{c}\text { Poor } \\
\text { in an elite } \\
\text { university } \\
\text { Tuition-paying } \\
\text { (good students) }\end{array}$} & \multicolumn{2}{|c|}{$\begin{array}{c}\text { Poor in top } 20 \% \text { at } \\
\text { Baccalaureate }\end{array}$} \\
\hline & (1) & (2) & (3) & (4) & (5) & (6) & (7) & (8) \\
\hline Camera & $\begin{array}{l}-0.025^{*} \\
(0.013)\end{array}$ & $\begin{array}{c}-0.025^{*} \\
(0.013)\end{array}$ & $\begin{array}{l}-0.025^{*} \\
(0.015)\end{array}$ & $\begin{array}{l}-0.026^{*} \\
(0.015)\end{array}$ & $\begin{array}{l}-0.025 \\
(0.031)\end{array}$ & $\begin{array}{l}-0.026 \\
(0.030)\end{array}$ & $\begin{array}{c}-0.022 * * * \\
(0.006)\end{array}$ & $\begin{array}{c}-0.019 * * * \\
(0.006)\end{array}$ \\
\hline Year FE & Yes & Yes & Yes & Yes & Yes & Yes & Yes & Yes \\
\hline County FE & Yes & Yes & Yes & Yes & Yes & Yes & Yes & Yes \\
\hline $\begin{array}{l}\text { County FE } \\
\text { x Yearly Trends }\end{array}$ & Yes & Yes & Yes & Yes & Yes & Yes & Yes & Yes \\
\hline Controls & No & Yes & No & Yes & No & Yes & No & Yes \\
\hline Observations & 15,821 & 15,821 & 10,023 & 10,023 & 5,798 & 5,798 & 142,214 & 142,214 \\
\hline R-squared & 0.043 & 0.048 & 0.043 & 0.050 & 0.064 & 0.069 & 0.048 & 0.066 \\
\hline
\end{tabular}

Notes: 1) The table displays the OLS estimates from the baseline DD specifications for the composition of students admitted at an elite university in 2009-2012. The dependent variable is: poverty status (dummy $=1$ for poor) of each student admitted at the elite university dummy (columns 16 ) and the poverty status (dummy $=1$ for poor) of each student scoring in the top $20 \%$ in our working sample of the 2009-2012 Baccalaureate (columns 7-8). The "Camera" treatment is defined as reported in the notes of Table 2.

2) Controls for the university admission sample: student's gender, track and dummy indicator for students who took the Baccalaureate before the year of university admission; controls for the Baccalaureate top 20\% sample: student's gender, track and a rural indicator.

3 ) The standard errors are clustered at county level (there are 42 clusters).

$* * *$ Significant at the 1 percent level.

** Significant at the 5 percent level.

* Significant at the 10 percent level. 